Review

\title{
Grid Synchronization and Islanding Detection Methods for Single-Stage Photovoltaic Systems
}

\author{
Rosa Anna Mastromauro \\ Department of Information Engineering (DINFO), University of Florence, 50139 Florence, Italy; \\ rosaanna.mastromauro@unifi.it; Tel.: +39-055-275-8650
}

Received: 29 April 2020; Accepted: 28 June 2020; Published: 1 July 2020

\begin{abstract}
Synchronization and islanding detection represent some of the main issues for grid-connected photovoltaic systems (PVSs). The synchronization technique allows to achieve PVS high power factor operation and it provides grid voltage monitoring. The islanding detection control function ensures safe operation of the PVS. Focusing on low-power single-stage PVSs, in this study the most adopted and the highest performance synchronization and islanding detection methods are discussed. The role of the synchronization system is fundamental to detect the grid conditions, for the islanding detection purpose, and to manage the reconnection to the grid after a PVS trip. Hence a combined review is advantageous.
\end{abstract}

Keywords: photovoltaic systems; synchronization systems; phase-locked loops; islanding detection methods

\section{Introduction}

At the end of 2018, the world had $152 \mathrm{GW}$ of installed photovoltaic (PV) electricity capacity. The best PV markets in 2018 were China with $44.3 \mathrm{GW}$, India with $10.8 \mathrm{GW}$, USA with $10.7 \mathrm{GW}$, Japan with $6.7 \mathrm{GW}$, Australia with $3.8 \mathrm{GW}$. The European Union (EU) has registered rise for the first time in years with $8.4 \mathrm{GW}$, but this growth is far from the 23.2 GW registered in 2011. However, the growth can be considered slow, some of the EU countries have already achieved high PV penetration due to past installations such as Germany with a PV overall capacity of 45.5 GW by the end of 2018, Italy that exceeds 20 GW, United Kingdom with 13 GW, Spain with 5.6 GW, Belgium with $4.3 \mathrm{GW}$ and Switzerland with $2.2 \mathrm{GW}$. It is estimated that overall, the PV systems (PVSs) had contributed to the $2.9 \%$ of the global electricity demand in 2018 and that the climate change impact is of 590 millions of tons of $\mathrm{CO}_{2}$ saving every year [1-3].

Due to the photovoltaic prize reduction and availability of loan products, a significant portion of PVSs have been recently installed also in absence of governments initiatives especially for residential applications. A performance evaluation of residential PVSs in some European countries is presented in [4]. Considering the period 2014-2016, the highest specific yield in $\mathrm{kWh} / \mathrm{kWp}$ has been registered in Italy in 2015.

The PVSs inverters price has diminished around 0.10 $\$ / \mathrm{Wp}$ in the last decade [5]. In addition, the design optimization of the PVS converters has facilitated the reduction of the total cost of ownership [6]. Nevertheless, the increase of PVS grid-connected installations implies several management challenges depending also on the point of interconnection between the PVS and the grid [7-10]. In this scenario advanced control features of the PVS inverters can contribute to overcome some of the grid management challenges due to high penetration [11-13].

Looking at the residential applications, the PVSs can be single-stage or double-stage. In case of single-stage PVSs, the PV array is directly connected to the inverter avoiding a boost DC/DC converter. Single-stage transformerless PVSs represent the most promising technology due to lower weight, higher efficiency, smaller size and limited cost than double-stage PVSs or single-stage architectures 
coupled to low-frequency transformers [14-18]. Focusing on a single-stage PVS, a review about some of the main control issues is presented in [19], however the analysis is limited to current and voltage control methods and maximum power point tracking (MPPT) techniques.

About the most important issues to be considered in grid-connected PVS there are the synchronization with the grid and the detection of the islanding condition. Synchronization deals with PVS high power factor operation, since the synchronization algorithms objective is to provide grid voltage information about amplitude, phase and frequency in order to generate a current/voltage reference which is in phase with the grid voltage [13,20-24].

Synchronization deals also with the grid voltage monitoring. According to the grid-connection requirements [25], the PVSs connected to the low-voltage distribution grid must operate without causing step change in the RMS voltage at the point of common coupling (PCC) exceeding $5 \%$ of rated value. In addition, the synchronization parameters limits for grid-connected PVS are: $0.3 \mathrm{~Hz}$ for the frequency difference, $10 \%$ for the voltage difference. Abnormal conditions can arise on the utility grid which require a prompt response from the grid-connected PVS, hence the information provided by the synchronization system are fundamental for this purpose [26-28].

Unintentional islanding phenomenon is verified in case of grid power outages when the PVS continues to supply the local loads. Unintentional islanding can cause damages to the local electrical loads, to the grid-connected PVS inverter, to the technicians during the maintenance operations. Numerous improved islanding detection algorithms have been proposed in literature in the last years aiming to detect islanding phenomenon in all possible cases [29-35]. However, many these algorithms are not designed peculiarly for PVS.

In case of low power residential PVSs and in particular in case of single-stage systems, the PVS inverter is commonly in charge of the islanding detection, hence the anti-islanding functionality represents one of the main challenge in the PVS inverters design [18]. The anti-islanding protections must be implemented on the basis of the international standards requirements for distributed power generation systems (DPGSs) [25,36-38]. In particular, it is required that unintentional islanding be detected in less than two seconds as already established in the previous guidelines for PVSs [39-41].

After a disconnection due to the islanding detection an improper reconnection event is not improbable if the PVS breaker connects the system to the grid when the PVS voltage is out of phase. In this hypothesis a second disconnection can occur due to the PVS protections action. Hence the reclosing procedure has to be managed in strict coordination with the PVS synchronization system. For this reason, synchronization and islanding detection issues must be analyzed together.

About synchronization systems some books have been published such as [42]. Few review papers can be found in literature [23,43-46]. In [43] all the main families of synchronization techniques (also including the artificial intelligence techniques) are classified showing advantages and disadvantages. Basic concepts about phase-locked loop (PLL) techniques are explained in [44]. Reference [45] is devoted to three-phase applications, reference [23] is devoted to single-phase application, while [46] is oriented to design issues.

About islanding detection methods many review papers have been published in literature considering different DPGSs [47-57]. Reference [47] provides a review of the islanding detection methods for high power DPGSs. In [48] an extensive review of the islanding detection methods is provided focusing on some performance indices evaluation and in particular on the detection time. Reference [49] is focused just on passive methods, reference [50] is focused just on active methods. In [51] the focus is on active and passive methods and a new active methods is proposed for a three-phase PVS. The same islanding detection methods are discussed also in [52] also including the hybrid detection methods. However, hybrid methods are categorized just as combination of active and passive methods. In [53] some active islanding detection techniques are compared on the basis of a new index assessing the non-detection-zone (NDZ) size. In [54] the active techniques are classified in two categories: techniques introducing positive feedback in the control of the inverter and techniques based on harmonics injection. In [55] the islanding detection methods based on different signal 
processing techniques are discussed in detail. Reference [56] provides a comprehensive review of the islanding detection techniques particularly oriented to recent intelligence-based methods. A similar approach is adopted in [57]. Intelligence-based islanding detection is out of topic in relation to the present study.

All the analyzed papers share as starting point a first classification among remote islanding detection techniques (based on communication) and local islanding detection techniques. Currently this classification can be overtaken considering the availability of communication protocols and local communication interface equipment by most PVS inverters.

No studies combining the analysis of the synchronization systems with the islanding detection techniques can be found in literature for PVSs or for other DPGSs applications. Nevertheless, many islanding detection schemes are based on modification or employment of additional synchronization systems to assess the unintentional islanding condition. In addition, independently of the adopted islanding detection technique, two synchronization systems are required in order to manage the reconnection procedure to the main grid by a PVS after an islanding event. Starting from this issues, the aim of this study is to provide a combined analysis about synchronization and islanding detection techniques which need coordinated operation and proper integration in the PVSs control structure.

Focusing on single-stage single-phase PVSs, the present study aims at giving an update of the most-recent trends about synchronization techniques and islanding detection methods, in particular: in Section 2 there are summarized the main goals of the single-stage PVSs control systems. The most adopted and the highest performance grid synchronization methods are analyzed in Section 3; while Section 4 is an overview of the islanding detection methods. Section 5 is about coordination between synchronization and islanding detection systems. Finally, the conclusions are presented in Section 6.

\section{Control System Functionalities of a Single-Stage photovoltaic Power System}

The overall control structure of a single-stage PVS is shown in Figure 1 where it is assumed that the PVS can be connected to a local load, to the utility grid or it can be part of a smartgrid. The control functionalities can be classified in basic control functions and ancillary control functions. The basic control functions are the maximum power extraction, the grid synchronization, the current and the voltage control, the unintentional islanding detection. High power factor operation and harmonic rejection are achieved by proper design of current and voltage controllers and of the synchronization system. The current/voltage control reference signal is provided by the PV source power control which consists of a maximum power point tracking (MPPT) algorithm and a DC voltage controller. The MPPT algorithm is in charge of the maximum power extraction.

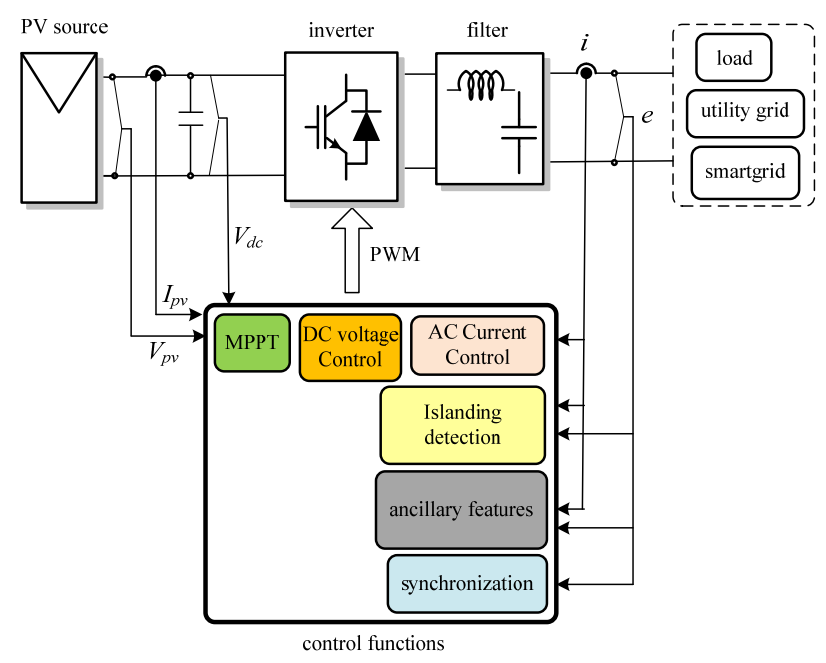

Figure 1. Single-stage photovoltaic systems (PVSs) control functions. 
The ancillary control functions are the ride-through capability, the voltage and the frequency support to the local loads or the main grid. The ancillary control functions are out of the scope of the present study.

\section{Grid Synchronization}

The phase angle of the grid voltage is a critical piece of information for grid-connected systems since it is used to obtain the control reference signal as previously pointed out. Numerous methods using different techniques for synchronization and grid-voltage monitoring have been presented in the technical literature about DPGS. Most of these studies are related to three-phase systems $[22,28,58,59]$ than to single-phase applications $[60,61]$. Some of the methods are not always categorized properly, thus leading to confusion. In order to clarify, the most used techniques can be organized as presented in Figure 2.

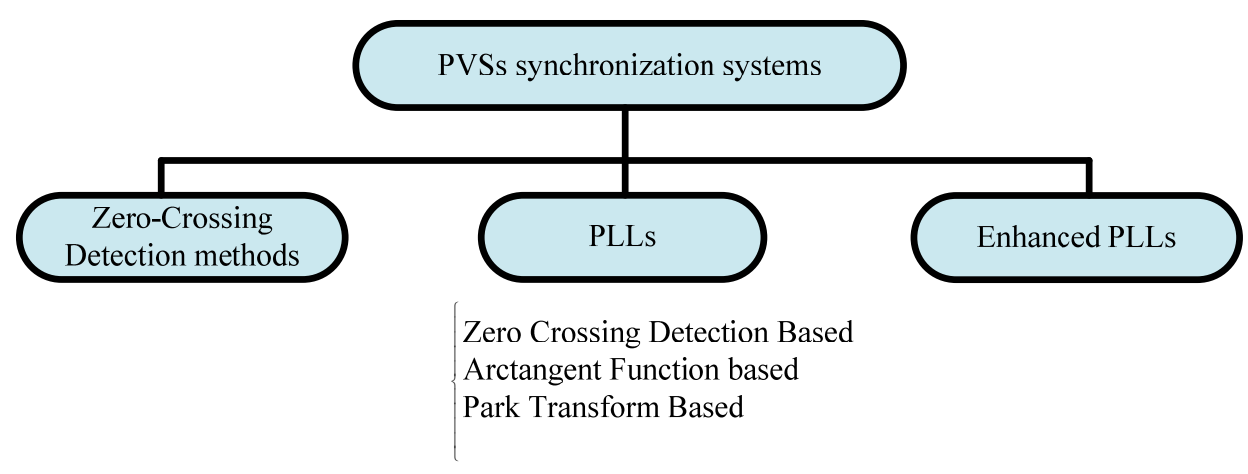

Figure 2. PVSs synchronization techniques classification.

Commonly the synchronization and grid voltage monitoring methods are classified in two main categories: zero-crossing detection (ZCD) methods [62] avoiding the grid voltage phase control, phase-locked loop (PLL) methods based on a strict control of the grid voltage phase [63]. The PLL techniques are generally categorized as PLL based on ZCD, on the arctangent function [64] and on the Park transform [44]. Among these, the Park transform-based PLL provides the best performance. Actually, in the last years, a new family of PLLs known as enhanced PLL has been ranked as the most promising.

Looking at the single-stage PVS shown in Figure 1, two synchronization systems are required in order to manage correctly the disconnections and reconnections with the main power system: the first synchronization system is used to monitor the voltage grid, the second one is used to monitor the PVS voltage. Among the synchronization systems presented in literature, only some methods are compatible with the considered application.

\subsection{Zero-Crossing Detection Methods}

An elementary method used to extract information about phase and frequency of the grid voltage is based on the zero-crossing measurement [62,65-67]. The ZCD structure is shown in Figure 3. When the grid voltage waveform crosses the zero, a counter provides in output information about the period and, consequently, the estimated frequency $\hat{\omega}$ of the grid voltage is obtained. The phase $\hat{\theta}$ of the grid voltage is achieved integrating $\hat{\omega}$. Despite the simplicity, this technique does not allow high dynamic performances. Indeed, the phase tracking can be fulfilled just for each half cycle of the grid voltage waveform. 


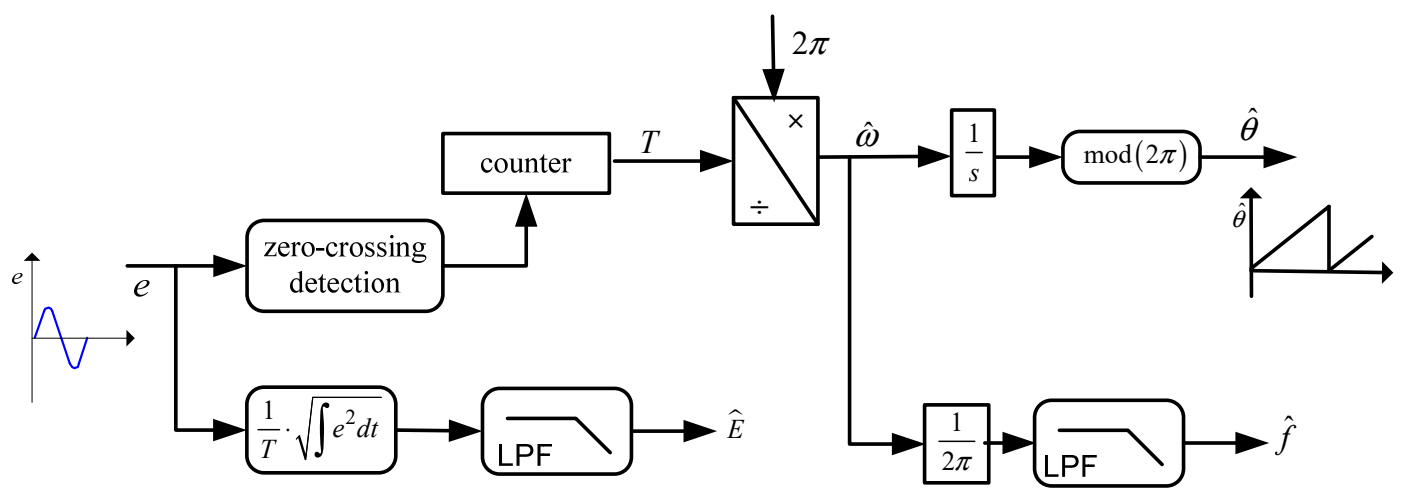

Figure 3. Zero-crossing detection (ZCD) structure.

Since the grid voltage $e$ is generally affected by power quality disturbances, a low-pass filter (LPF) is used to extract the fundamental frequency $\hat{f}$ of the original signal. No controller is employed in the detection and the method is not proper to track and to monitor the grid voltage in case of abrupt changes.

\subsection{PLLS}

The PLL consists of a phase comparator and a PI controller. The phase comparator determines the phase error $\varepsilon$ which is provided in input to the PI. A reference frequency $\omega_{I C}$ and the output of the PI are summed in order to evaluate the grid voltage frequency $\hat{\omega}$. The feed-forward action allows to improve the PLL dynamic performance. Later the grid voltage angle $\hat{\theta}$ is calculated by the information of the grid voltage frequency. The phase comparator operation can be based on a reference signal provided by the ZCD of the input grid voltage, by the arctangent function of by the Park transform.

In case of ZCD PLL, the ZCD discussed in the previous subsection is employed to extract the phase reference for the phase comparator [42,68]. As described before, also this synchronization system is not proper to track the grid voltage in case of abrupt variations. However, the ZCD PLL provides better performance than the ZCD technique since the estimated angle $\hat{\theta}$ is controlled in closed loop.

Both the arctangent function-based PLLs and the Park transform-based PLLs require a voltage orthogonal system. In case of the arctangent function-based PLL $[42,64]$, the phase reference for the phase comparator is extracted calculating the arctangent by $e_{\alpha}$ and $e_{\beta}$ information. The disadvantage is that the arctangent function is not easy to implement.

In Figure 4 there is shown the structure of a PLL-based on the Park transform which represents the most adopted solution.

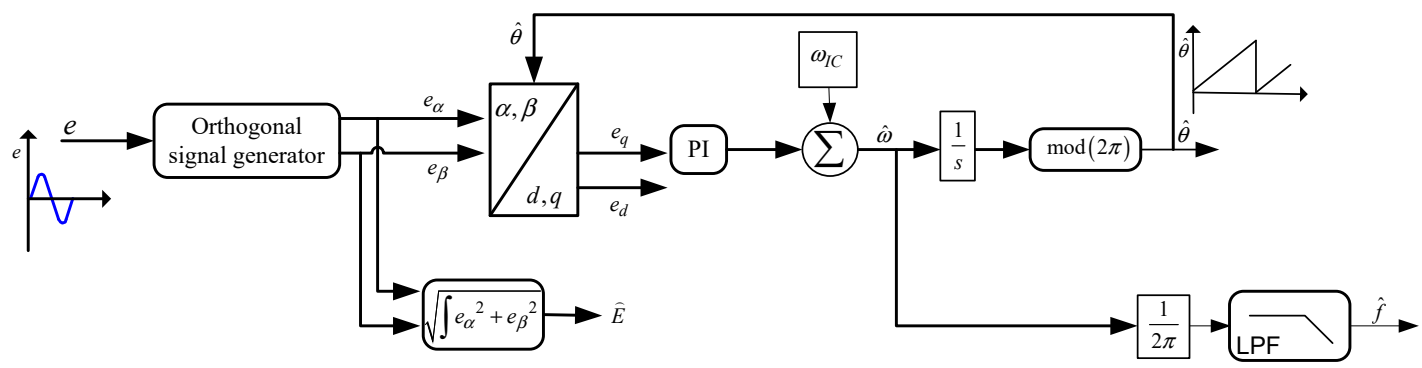

Figure 4. Phase-locked loop (PLL) structure based on the Park transform.

A coordinate transformation from $\alpha \beta$ to dq is usually adopted to process DC signals instead of AC signals. The grid voltage phase angle is extracted synchronizing the grid voltage vector with the dq rotating reference frame. Forcing the q-axis voltage reference to zero, the lock with the grid voltage is ensured [69]. The error signal is processed by a PI. The output of the PI controller is the grid frequency. 
The estimated frequency is integrated; hence the grid voltage phase angle is measured, and the result is provided in input to the $\alpha \beta$-dq transformation block. As shown in Figure 4, the phase detection is based on the Park transform [70] while the PI controller acts as a filter which determines the dynamics of the phase lock. For this reason, the PI controller parameters are chosen considering the tradeoff between filtering performance and fast dynamics [46].

All the PLLs described up to now need a LPF as in case of the ZCD synchronization method. It occurs to extract the fundamental frequency $\hat{f}$ of the original signal $e$ which is commonly affected by harmonic disturbances. Neglecting the LPF, the detailed structure of the PLL based on the Park transform is depicted in Figure 5 for a better understanding of how the phase comparator is obtained through the use of the Park transform.

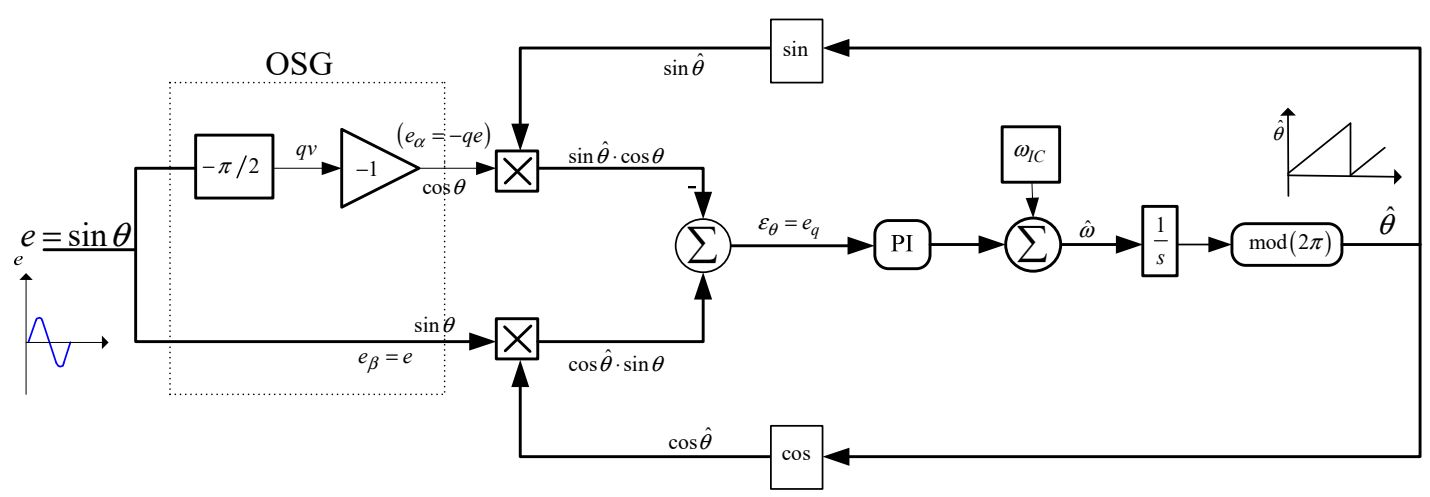

Figure 5. Detailed PLL structure based on the Park transform.

In case of single-phase systems, the orthogonal voltage system has to be artificially generated [21,71] and it represents the main challenge for the grid voltage monitoring. The orthogonal signal generator (OSG) is in charge of the orthogonal voltage system realization. One of the most advanced technique adopts the second order generalized integrator (SOGI) [72,73]. The OSG based on the SOGI filter allows also to extract the fundamental component of the grid voltage, for this reason the LPF used to extract $\hat{f}$ can be avoided in case of the SOGI PLL. The OSG based on the SOGI filter is shown in Figure 6.

The grid voltage $e$ is transformed in two sinusoidal signals denoted as $e^{\prime}$ and $q e^{\prime} . e^{\prime}$ and $q e$ are phase shifted of $\pi / 2$. The sinusoidal signal $e^{\prime}$ is in phase with the grid voltage $e$. In addition, $e^{\prime}$ and the first harmonic component of the grid voltage exhibit the same magnitude.

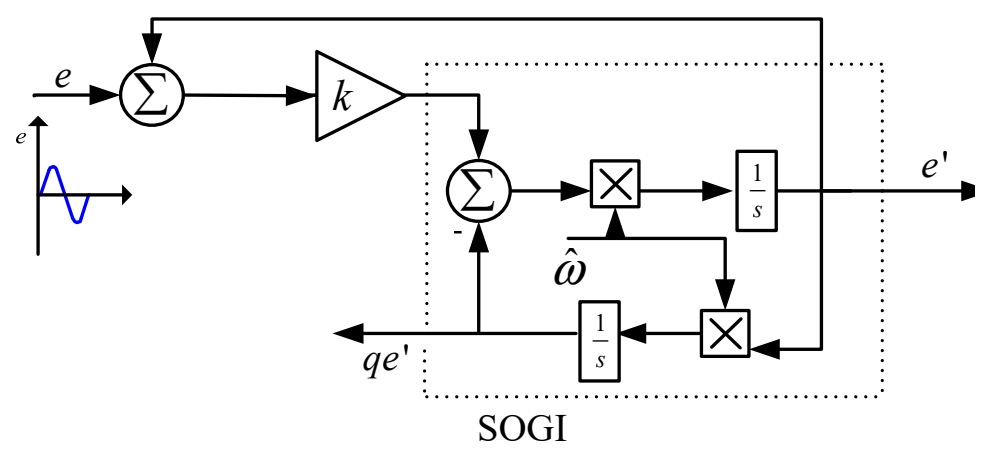

Figure 6. Orthogonal signal generator (OSG)-second-order generalized integrator (SOGI) standard structure.

The SOGI acts like an infinite gain band-pass filter whose transfer function is defined as:

$$
H_{S O G I}(s)=\frac{\omega_{n} s}{s^{2}+\omega_{n}^{2}}
$$


where $\omega_{n}$ represents the undamped natural frequency of the SOGI which should coincide with the estimated frequency $\left(\omega_{n}=\hat{\omega}\right)$.

The performances of all the single-phase PLLs based on a OSG are particularly affected by the voltage offset commonly introduced by the measurement equipment and by the signal processing operation [27]. The frequency of the error derived by the grid voltage offset is the same of the grid voltage waveform. The PLLs based on a OSG are not properly designed to provide rejection to the voltage offset. However, since the PI controller acts as a filter, the PLL controller parameters could be tuned in order to achieve filtering of the voltage offset. It would modify the bandwidth of the overall system, but, unfortunately, it would impact considerably the dynamic performances of the PLL. In [71] the performances of single-phase PLLs based on different OSGs are compared and a guideline for the PLLs parameters tuning is proposed.

\subsection{EPLLS}

In the last years, an alternative synchronization technique known as enhanced phase-locked loop (EPLL) has succeeded [23,74] due to high filtering performance. It consists of an adaptive nonlinear detection algorithm which provides two orthogonal signals synchronized with the grid voltage. The EPLL structure is represented in Figure 7. It allows to estimate the frequency, the phase and also the amplitude $E_{E P L L}$ of the input signal fundamental component. The EPLL operates as an adaptive filter (either a notch or a band-pass filter) whose frequency tracks the fundamental frequency of the grid voltage. $e_{E P L L}$ denotes the filtered signal tracking the grid voltage supplied in input.

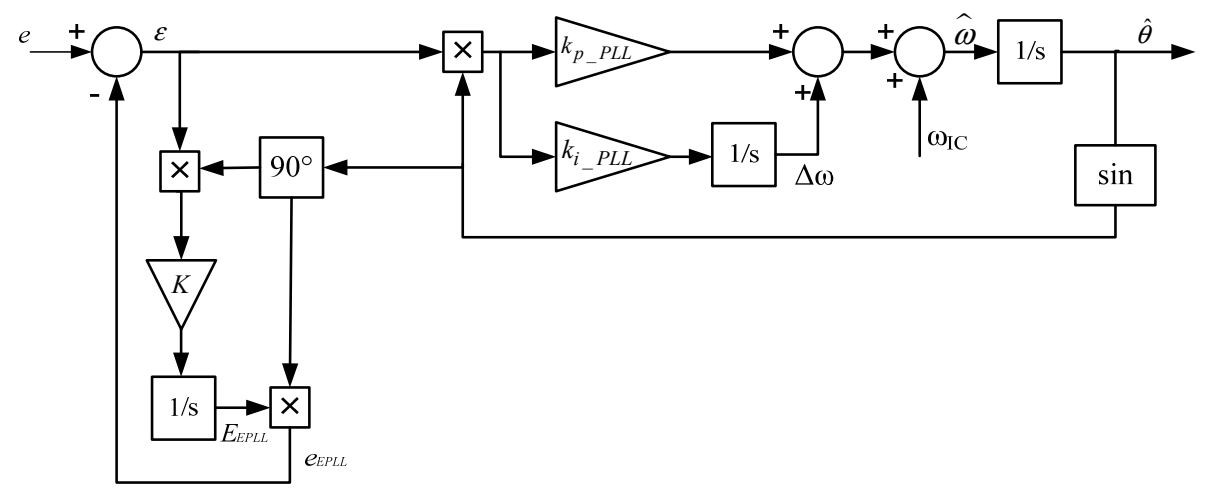

Figure 7. Enhanced phase-locked loop (EPLL) structure.

The EPLL represents one of the most promising synchronization systems for single-phase applications since it provides: filtering capability in respect to the undesired harmonics, adaptive detection of the grid voltage fundamental frequency, proper estimation of frequency, angle and amplitude of the grid voltage supplied in input [24,75]. Some modifications of the EPLL have been also proposed in the most recent literature, in particular in [76] the structure of the EPLL has been modified in order to achieve a linear model.

The main differences of the EPLL compared to the PLL based on the Park transform occur testing the two systems in presence of grid voltage perturbations, in particular frequency changes and harmonics. It has been demonstrated that the EPLL exhibits higher filtering capability and shorter transients $[23,77]$. For all these reasons the EPLL represents the ideal candidate to operate in coordination with the islanding detection techniques discussed in the following Section.

\section{Islanding Detection}

In case of grid disconnection, the PVS operation depends on the power level provided by the PVS before islanding occurrence. In Figure 8 it is represented the PVS power stage for the islanding detection test. The grid utility breaker is denoted as $\mathrm{Sg}$, two different breakers $S_{1}$ and $S_{2}$ are used to connect the PVS to the point of common coupling (PCC) and to connect the load. A variable RLC 
load is considered in order to assess the islanding phenomenon in case of different load powers and quality factors.

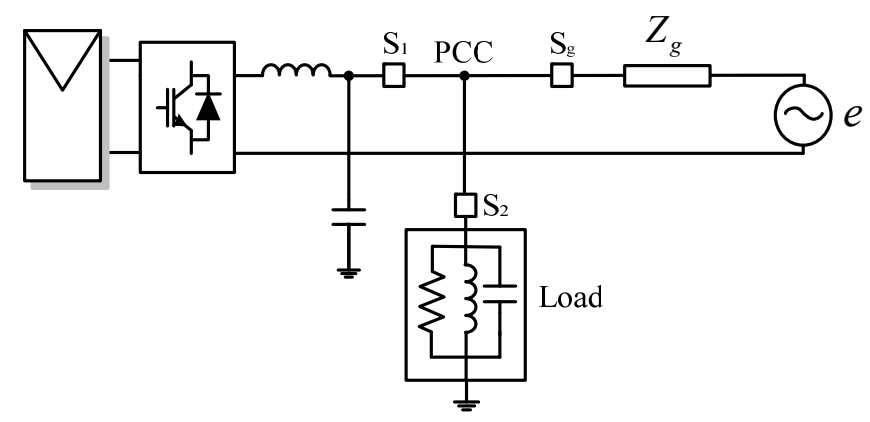

Figure 8. Photovoltaic system (PVS) power stage for islanding detection test.

For each islanding detection method, the non-detection-zone (NDZ) defines the area where the anti-islanding methods fail to detect islanding. As a consequence, the NDZ can be used as a performance index to assess the islanding detection methods [78-80]. However, in comparison with the previous version of the standard [81], the new standard [25] requires voltage and frequency ride-through capability of the PVSs which increases the NDZ of the islanding detection algorithms. Hence it has to be pointed out that ride-through requirements hazard the islanding detection techniques.

Traditionally the islanding detection methods were classified in remote techniques (based on communication signals) and local techniques. Considering the recent advancements of communication equipment and the requirements updates related to the PVS standards, in this study a different classification is adopted. The islanding detection methods are classified in four main categories: Communication-based methods [82], passive methods [49], active methods [25,50] and signal processing-based methods [55]. In addition, in order to improve the performance of the islanding detection methods and to satisfy the standard requirements, hybrid techniques are developing in the last years which are based on combination of the previous categories. In Figure 9 the main islanding detection methods are summarized.

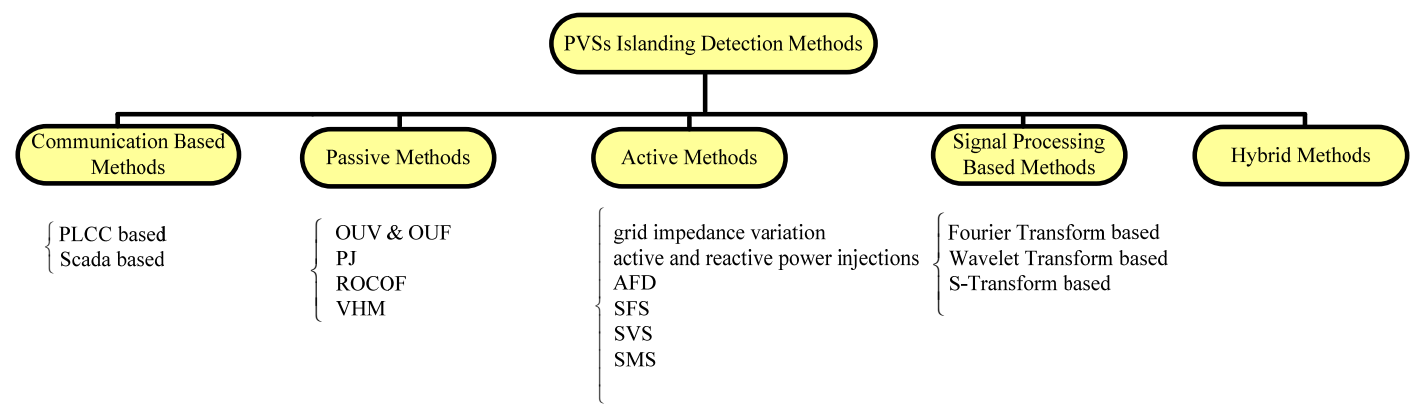

Figure 9. PVSs islanding detection methods classification.

\subsection{Communication-Based Methods}

Communication-based methods allow to achieve accurate and reliable assessment of the islanding conditions. Otherwise, considering the number of PVSs to be managed and the power size, the required equipment can vary $[82,83]$. Hence these solutions are not common in case of low voltage and low power residential PVSs. The communication-based methods can be classified in: power line carrier communication (PLCC) methods, Supervisory Control Moreover, data acquisition (SCADA)-based methods. 


\subsubsection{PLCC-Based Methods}

The PLCC-based methods allow a continuous test of the grid connection. A continuous carrier is adopted [84-87] and all the PVSs are equipped with a receiver. When the grid breaker Sg is opened as a consequence of grid disconnection, the receivers do not catch signals and the islanding condition is detected. The PLCC-based techniques are particularly resilient to noise since the PVSs inverters switching frequencies do not influence the PLCC signals.

\subsubsection{SCADA-Based Methods}

The SCADA-based methods assess the status of the breakers connecting the PVSs to the grid $[57,88,89]$. Using the SCADA methods, the coordination between the PVS and the grid utility operations is significantly improved, and the islanding phenomenon can be detected avoiding a NDZ area. Cost and complexity of the equipment represent the main disadvantages.

\subsection{Passive Methods}

Compared to the communication-based methods, the passive islanding detection methods present simple implementation based on protection relays and synchronization systems [41,49]. The most famous passive methods are over/under voltage (OUV) and over-under frequency (OUF), phase jump $(\mathrm{PJ})$, rate of change of frequency (ROCOF), voltage harmonic monitoring (VHM).

\subsubsection{OUV and OUF Methods}

All grid-connected PVS inverters are required to have OUV and OUF protections. The aim is to avoid power supply by the PVSs when the voltage amplitude and frequency values at the PCC are different from set values [41,90].

Considering an RLC load whose resonant frequency is equal to the grid frequency, no reactive power absorption is verified by the load. In case of grid disconnection, the power absorbed by the load is equal to the active power provided by the PVS. Hence the RMS value of the voltage provided by the PVS at the PCC changes from $E_{P V S}=E$ before the disconnection to:

$$
E_{P V S}=\delta E
$$

where $E$ is the rated RMS value of the grid voltage,

$$
\delta=\sqrt{\frac{P_{P V S}}{P_{L}}}
$$

$P_{P V S}$ is the active power supplied by the PVS, $P_{L}$ is the rated load active power.

In conclusion the voltage value at the PCC increases or decreases depending on the PVS power generation. As a consequence, also the reactive power changes on the basis of the following relationship:

$$
Q_{P V S}=\left(\left(\frac{1}{L \omega_{P V S}}\right)-C \omega_{P V S}\right) E_{P V S}^{2}
$$

In (4) $L$ and $C$ are the inductive and capacitive components of the RLC load, $\omega_{P V S}$ denotes the voltage frequency at the PCC after the grid disconnection. Hence it results:

$$
\omega_{P V S}=\frac{-\left(\frac{Q_{P V S}}{E_{P V S}^{2} \mathrm{C}}\right)+\sqrt{\left(\frac{Q_{P V S}}{E_{P V S}^{2} \mathrm{C}}\right)^{2}+\frac{4}{L C}}}{2}
$$

The voltage frequency and amplitude variations allow to detect islanding operation. Unfortunately, in case of power balance between the PVS generation and the load, no active and reactive power 
variations are registered and consequently no voltage frequency and amplitude variations can be measured. Similarly, small active and reactive power variations imply small voltage variations in terms of frequency and amplitude. For this reason, the OUV and OUF protection cannot detect islanding. OUV and OUF protections are considered insufficient anti-islanding techniques since the active and reactive power variations due to the islanding phenomenon are commonly limited and, as a consequence, there is high probability to fall into the NDZ.

\subsubsection{Phase Jump Method}

The aim of the phase jump (PJ) method is the detection of a "jump" between the PVS inverter current and voltage [78]. The PJ technique represents one of the first anti-islanding methods and it is based on the use of synchronization systems extracting information about the current and the voltage phase. However, considering the present availability of fast PLLs and the development of high performance current controllers, voltage and current synchronization could be achieved also during islanding operation. Consequently, the detection of the islanding phenomenon based on this technique could fail.

\subsubsection{Rate of Change of Frequency Method}

The ROCOF islanding detection method measures the rate of change of frequency $d f / d t$ in a set time window. When the grid is disconnected, the power mismatch between generation and load causes frequency variations. The PVS is tripped when $d f / d t$ exceeds the threshold value [91,92]. The threshold setting is the main issue of this method since it is necessary to distinguish islanding from load changes. Besides the ROCOF exhibits a wide NDZ combined with slow dynamics.

\subsubsection{Voltage Harmonic Monitoring Method}

The voltage harmonic monitoring (VHM) method is based on the voltage harmonic distortion estimation to detect the occurrence of the islanding phenomenon [49]. In grid-connected operation the voltage at the PCC is set by the grid, but, in case of grid disconnection, the PVS inverter determines the voltage at the PCC. Nevertheless, the voltage harmonic distortion varies with the grid impedance and it depends on the loads connected to the PCC. As a consequence, the accuracy of the method can be hazarded if the islanding detection thresholds are not properly set. Better performance can be achieved monitoring some selected harmonics variations rather than the overall voltage harmonic distortion. In this hypothesis the harmonics variations can be detected by means of PLLs tuned in order to track the selected harmonic components.

\subsection{Active Methods}

The active islanding detection methods are developed with the goal to achieve better performance than the passive methods. The active methods introduce a perturbation in the PVS through the injection of an active signal $[50,93]$. The active signal injection is designed considering starting from ideal operating conditions of the PVS. The main active methods can be classified in: Grid impedance variation methods, active and reactive power injections methods, active frequency drift (AFD), Sandia frequency shift (SFS), Sandia voltage shift (SVS), slip-mode frequency shift (SMS).

\subsubsection{Grid Impedance Variation Methods}

Islanding phenomenon assessment can be based on grid impedance variations monitoring [78,94,95]. A small harmonic current component is drained into the PVS. The grid impedance is evaluated at the frequency of the injected harmonic component. Additional equipment can be employed to measure the grid impedance. Otherwise the grid impedance measurement can be embedded in the PVS inverter control system. 
Stability and power quality issues must be tackled when this technique is applied to numerous PVS connected in parallel due to the combination of the injected perturbations and possible inter-harmonics.

\subsubsection{Active and Reactive Power Injections Methods}

The rationale of the active power injections method is to use controlled active power injections causing active power variations $\Delta P_{P V S}$ in the PVS. Consequently, voltage variations can be observed exceeding the threshold voltage value of the islanding protections [50]. Assuming a resistive load $R$, whose power $P_{L}$ is constant, it is possible to express the power provided by the PVS as function of the voltage at the PCC. In case of islanding condition, it results:

$$
P_{P V S}=P_{L}=\frac{E_{P V S}{ }^{2}}{R}
$$

Hence it can be obtained:

$$
\frac{\partial P_{P V S}}{\partial E_{P V S}}=2 \cdot \frac{E_{P V S}}{R}=2 \cdot \frac{\sqrt{R \cdot P_{P V S}}}{R}=2 \cdot \sqrt{\frac{P_{P V S}}{R}}
$$

The voltage variation can be evaluated as:

$$
\Delta E_{P V S}=\frac{\Delta P_{P V S}}{2} \cdot \sqrt{\frac{R}{P_{P V S}}}
$$

The method is effective but is requires some tuning procedure in order to avoid overcurrents due to the active power injections. The disadvantage is that the islanding technique has to be coordinated with the MPPT operation. Hence the main challenge is to determine when the active power injection can be applied without jeopardizing the other control functions.

Similarly, reactive power injections can be used to cause reactive power variations $\triangle Q_{P V S}$ in the system [96]. As a consequence, frequency variations are obtained exceeding the frequency threshold value and islanding condition can be detected.

\subsubsection{Active Frequency Drift}

The active frequency drift (AFD) is based on a perturbation of the PVS inverter current. In particular, the PVS inverter current reference is modified adding a disturbance current [29]. Denoting as $T$ the period of the grid voltage, it occurs that the PVS inverter current is null for a time portion indicated with $t_{c}$ in each half cycle as shown in Figure 10.

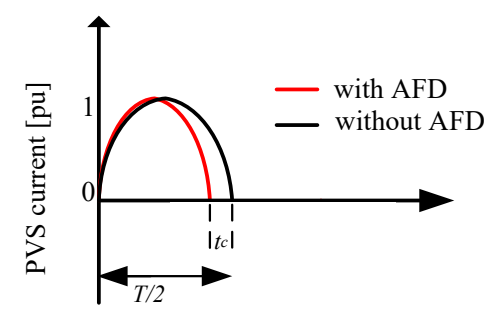

Figure 10. Half wave of the PVS inverter current with and without active frequency drift (AFD).

During grid-connected operation the PVS inverter voltage is not affected by the perturbation. Differently in islanding operation the PVS inverter voltage "drifts" up or down as a consequence of the continuous inverter current variation. The frequency change has to be detected by the UOF protections. Successively the PVS is promptly disconnected. 
The AFD method is characterized by a chopping factor $c$ which measures the amount of the perturbation:

$$
c=\frac{2 t_{c}}{T}
$$

The method ensures correct islanding detection and simple implementation, but the main disadvantage is the power quality detriment due to the current variation. Hence the method is not appropriate in case of numerous PVSs connected in parallel.

\subsubsection{Sandia Frequency Shift}

The Sandia frequency shift (SFS) methods derives from the AFD technique. SFS perturbs the PVS adding a dead-time to the PVS inverter reference current. Hence the inverter current exhibits a phase "shift" [29,97-99].

For this method, the chopping factor $c_{S}$ is defined as:

$$
c_{S}=c_{S o}+k_{S F S}\left(f_{P V S}-f\right)
$$

where $k_{S F S}$ is a proportional gain, $c_{S o}$ is the chopping factor in absence of frequency error, $f$ is the grid frequency and $f_{P V S}$ is the output frequency of the PVS inverter.

When the PVS is connected to the grid, the frequency error is null since the grid sets the frequency at the PCC. On the contrary, during islanding operation, the frequency error is not negligible. As a consequence, the PVS inverter current grows in order to overcome the phase shift, the chopping frequency increases, and the frequency varies beyond the OUF threshold values. Hence islanding is detected.

The SFS NDZ is smaller than the AFD NDZ. The improved islanding detection performances are achieved to the detriment of the power quality performances. In addition, in case of high PVSs penetration, unexpected transient disturbances can be registered.

\subsubsection{Sandia Voltage Shift}

The Sandia voltage shift (SVS) method operates with positive feedback of the PCC voltage amplitude $[29,100]$. During grid-connected operation of the PVS no significant variations are observed. In case of disconnection of the grid, voltage variations are monitored at the PCC. As a consequence, also the PVS inverter voltage varies and later the PVS is tripped since the voltage variations exceed the OUV protections threshold values. The NDZ of the SVS method is very small. However, the power quality is worsened and also the efficiency is reduced since the power processed by the inverter varies.

\subsubsection{Slip-Mode Frequency Shift}

The slip-mode frequency shift (SMS) detects islanding phenomenon using positive feedback to lead the PVS towards instability in case of grid disconnection $[80,101,102]$. In case of grid disconnection, the PVS frequency changes naturally. The PVS PLL action can be modified in order to increase the frequency rate of change rather than to annul it. The phase is forced to be a function of the voltage frequency at the PCC. The PLL acts to increase the frequency until the PVS inverter voltage phase grows faster than the phase of the RLC load (unstable region). The PVS is tripped when the inverter voltage frequency exceeds the threshold value. The method can fail when the load phase slope is higher than the slope achieved by the SMS technique. In this case instability could not be recognized.

In Figure 11 there is shown how the action of the PVS PLL is modified on the basis of the SMS rationale. The PVS phase angle changes from $\hat{\theta}_{P V S}$ to $\theta_{S M S}$. 


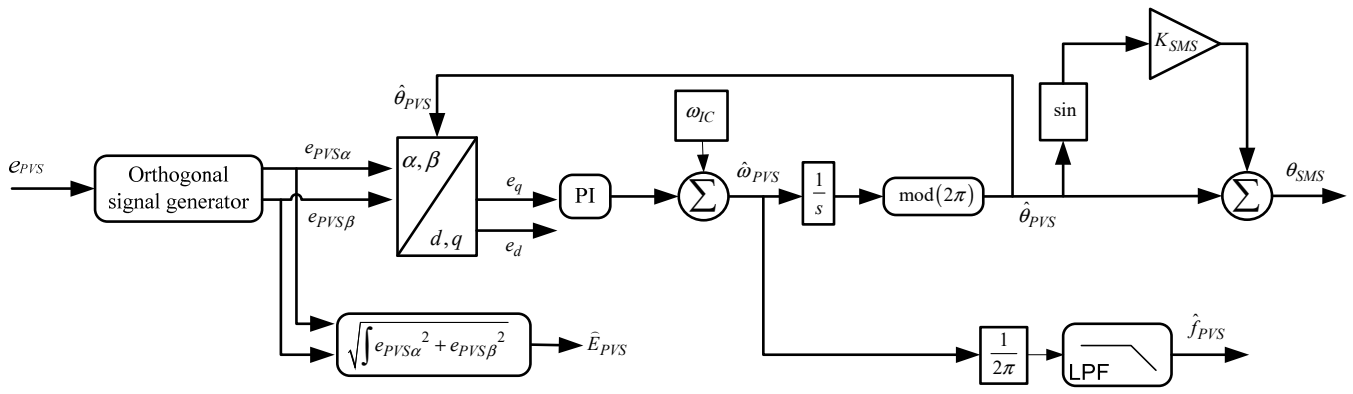

Figure 11. PVS PLL operation in case of SMS islanding-detection technique.

\subsection{Signal Processing-Based Methods}

Signal processing techniques can be adopted to design new islanding detection algorithms or to improve the performance of the previous developed algorithms $[55,82]$. The signal processing islanding detection methods are generally based on (a) Fourier transform; (b) wavelet transform and (c) S-transform.

\subsubsection{Fourier Transform-Based Methods}

The PVS output power is typically affected by variations after grid disconnection, as a consequence, its spectrum varies with continuity in a certain frequency range. Fourier transform (FT) is not proper for the analysis of non-stationary signals. Hence it cannot provide information about fluctuating signals linked to the islanding occurrence [103]. For this reason, the application of this signal processing technique to the analysis of transient phenomena such as islanding is not very common. However, some islanding detection techniques based on the Discrete Fourier transform (DFT) and its modifications have been discussed in literature [104,105]. In [104] a modified VHM islanding detection technique is proposed. Since the equivalent harmonic components measured at the PCC change in case of islanding occurrence, the DFT is employed to assess harmonic components variations. Differently in [105] a kind of FT, named Goertzel algorithm, is employed to develop an active islanding detection method where the Goertzel algorithm extracts the magnitude and phase of some selected components with limited computational burden.

\subsubsection{Wavelet Transform-Based Methods}

Filters based on the wavelet transform (WT) can track the PVS output power spectrum variations in a certain frequency range. Indeed, WT can process simultaneously signals varying in time and in frequency also in case of non-stationary waveforms. The signal to be processed is decomposed in different levels and the coefficient vectors of each level vary with the signal length. Numerous islanding detection methods based on different mother wavelets were developed [106-111]. As an example, in [108] the multiresolution analysis (MRA) based on the WT is employed to break down the DPGS voltage into different scales. In [109] the WT is adopted just to enhance the performance of the conventional islanding detection methods. In [110] the WT and the back propagation neural network (BPNN) are combined to provide a new islanding detection method based on the normalized logarithmic energy entropy estimation. In [111] the islanding detection technique is based on localization of high-frequency harmonics due to the PVS inverter switching. WT-based algorithms provide generally high performance islanding detection techniques with limited computational burden and implementation complexity. On the contrary these techniques suffer particularly for noise.

\subsubsection{S-Transform-Based Methods}

S-transform (ST) represents a superior signal processing technique which was born to overcome the noise sensitivity issue of the WT. Various high performance islanding detection techniques based on the ST have been proposed in [112-114]. In [112,113] there are compared the performances of 
the ST and of the WT. Better results in terms of islanding detection and localization are obtained using the ST instead of the WT. Similar results are achieved in [114] where the islanding detection method is based on the analysis of the negative sequence voltage. For this reason, the method cannot be applied to single-phase PVS avoiding modifications. However, it is demonstrated that the use of the ST results particularly advantageous to detect islanding condition also in presence of noise. In conclusion, higher performances are ensured in the islanding detection since S-transform allows the extraction of the phase of each frequency component related to the time-varying signals involved in the islanding phenomenon. Nevertheless, these techniques require more computational burden than the WT-based methods.

\subsection{Hybrid Methods}

In the present standard [25], it is established that any requirements for ride-through shall not be falsely inhibited by any methods or design features utilized to meet the unintentional islanding detection when an actual unintentional island condition does not exist. Conversely, the unintentional islanding detection requirements shall not be inhibited by ride-through during valid unintentional islanding conditions.

Passive methods operating alone cannot provide satisfying results considering their poor islanding detection performance and the need to ensure ride-through capability by the PVS. Better results can be obtained using active methods, but the power quality is often affected.

Taking into account also the recent advancement in computing capability and communication systems, hybrid islanding detection techniques, based on combinations of the four categories previously discussed, represent the most promising techniques [115-125]. Starting from combination or modification of conventional methods, in [115] some islanding detection methods are proposed as integration of well-known passive methods. In [116] a modified active SVS method is presented, and the modulation index is used as injected signal to achieve the voltage magnitude shift and to detect the islanding phenomenon. In [117] a hybrid active method is developed combining a threshold filter (based on a binary tree classifier) with a harmonic amplification factor used as perturbation to detect islanding. In [118] a modified active islanding detection method is obtained varying the amplitude of the PVS current periodically. In this case islanding occurrence is detected through the AFD method when high current variations are registered. In [119] an active technique is obtained combining the AFD with the SMS. In [120] a new active islanding detection method is proposed and based on the droop control theory. The droop control is modified considering a correlation function between the frequency and the reactive power. This function is used to detect the islanding condition. Moving towards more innovative solutions, in [121] a new islanding detection technique is based on the addition of a variable impedance and a hybrid automatic transfer switch. In [122] computational geometry has been applied to derive an islanding detection technique based on a classifier module. As in case of the active methods, the technique discussed in [123] uses harmonic current injection. The islanding condition is detected through cross correlation. In [124] an original islanding detection scheme based on machine learning adoption is proposed. In [125] a communication-based islanding detection method is presented based on a wireless sensors network. The performances are improved adding a combination of selected loads in the system in order to avoid excessive voltage variations.

\subsection{Performances Evaluation of the Islanding Detection Methods}

The performances of the considered islanding detection categories are reviewed in Table 1. The main advantages and disadvantages related to the same categories are summarized in Table 2. The hybrid methods are combinations of the islanding detection techniques categorized as communication-based methods, passive methods, active methods and signal processing-based methods. The performances of the hybrid methods depend on the original characteristics of the techniques that they match, hence hybrid methods are not reported in Tables 1 and 2. The hybrid methods are designed to overcome the disadvantages of the islanding detection techniques previously 
developed. As a consequence, hybrid methods are progressively updated, and they can be assessed as tradeoff among advantages of the original methods and increased implementation complexity.

Table 1. Performances of the islanding detection methods.

\begin{tabular}{ccccc}
\hline & Communication-Based Methods & Passive Methods & Active Methods & Signal Processing-Based Methods \\
\hline Accuracy & high & poor & high & high \\
NDZ area & absent & wide & limited & absent or limited \\
Dynamics & fast & generally fast & medium slow & fast \\
Impact on the grid & no & no & medium or significant & no \\
Price & high & limited & limited & high \\
\hline
\end{tabular}

Table 2. Advantages and disadvantages of the islanding detection methods.

\begin{tabular}{|c|c|c|c|c|}
\hline & $\begin{array}{c}\text { Communication-Based } \\
\text { Methods }\end{array}$ & Passive Methods & Active Methods & Signal Processing-Based Methods \\
\hline Advantage & reliability & simplicity & $\begin{array}{c}\text { accuracy } \\
\text { relative simplicity }\end{array}$ & accuracy \\
\hline Disadvantage & $\begin{array}{l}\text { expensive with regard to low } \\
\text { power PVSs }\end{array}$ & $\begin{array}{l}\text { erroneous } \\
\text { detection in case of } \\
\text { power balance } \\
\text { between generation } \\
\text { and load } \\
\text { improper } \\
\text { estimation due to } \\
\text { ride-through } \\
\text { requirements } \\
\text { compliance }\end{array}$ & $\begin{array}{l}\text { power quality detriment } \\
\text { stability hazard in case of } \\
\text { numerous PVSs connected } \\
\text { in parallel }\end{array}$ & complexity \\
\hline
\end{tabular}

\section{Synchronization and Islanding Detection Coordination}

ZCD methods and ZCD-based PLLs exhibit low dynamic performance and are not suitable for grid voltage monitoring in case of abrupt changes of the grid voltage and power quality disturbances. Arctangent-based PLLs are not particularly widespread due to implementation issues. The PLLs based on Park transform and SOGI OSG, known as SOGI PLLs and the EPLLs represent the most promising synchronization systems for single-phase PVSs due to high filtering capability, also in presence of grid voltage harmonic distortion, accuracy and high dynamic performances also in case of grid voltage abrupt variations. SOGI PLLs and EPLLs are ideal candidates to be employed in the islanding detection and in the reconnection of a PVS to the main grid after an islanding event.

\subsection{Impact of the Synchronization Systems on the Islanding Detection Methods}

Many islanding detection methods are based on information about the amplitude, the phase and the frequency of the PVS voltage. These methods do not require additional synchronization systems to be included in the PVS control structure. The SOGI PLLs and the EPLLs represent the best synchronization systems for this kind of applications. Other islanding detection techniques require additional synchronization systems in order to monitor some selected harmonics and the PVS current or can require some modification of the synchronization system generally used to track the PVS voltage. There are also some islanding detection techniques which are not based on synchronization systems information. In Table 3 there are reported the main devices used by the different islanding detection methods discussed in Section 4. The islanding detection methods which employ PLLs or EPLLs are pointed out. Hybrid methods are not included in Table 3 since their characteristics depend on the original methods that they combine.

Looking at Table 3, it can be observed that both communication-based techniques and signal processing-based techniques avoid the use of PLLs. Indeed, the communication-based islanding detection techniques are based on communication interface equipment, in particular receivers. The signal processing-based techniques are based on harmonics measurement and localization related to time-varying electrical signals such as voltage, power, entropy, etc. The harmonics decomposition is achieved through the use of the FT, the WT or the ST. 
Table 3. Main devices of the islanding detection techniques.

\begin{tabular}{|c|c|c|}
\hline & Method & Devices \\
\hline \multirow{2}{*}{ Communication-based } & PLCC-based & \multirow{2}{*}{ Receivers } \\
\hline & SCADA-based & \\
\hline \multirow{4}{*}{ Passive } & OUV/OUF & \multirow{2}{*}{$\begin{array}{l}\text { Solid-state relays or PLLs/EPLLs } \\
\text { coordinated with relays }\end{array}$} \\
\hline & ROCOF & \\
\hline & PJ & $\begin{array}{l}\text { Additional PLL/EPLL for } \\
\text { current monitoring }\end{array}$ \\
\hline & VHM & $\begin{array}{l}\text { Additional PLLS/EPLLS for } \\
\text { voltage harmonics monitoring }\end{array}$ \\
\hline \multirow{6}{*}{ Active } & Grid impedance variation & Impedance measurement \\
\hline & Active and reactive power injections & \multirow{4}{*}{$\begin{array}{l}\text { Solid-state relays or PLLs/EPLLs } \\
\text { coordinated with relays }\end{array}$} \\
\hline & AFD & \\
\hline & SFS & \\
\hline & SVS & \\
\hline & SMS & Modified or additional PLL/EPLL \\
\hline \multirow{3}{*}{ Signal-processing-based } & FT-based & \multirow{3}{*}{$\begin{array}{l}\text { Harmonics measurement and } \\
\text { localization of electrical } \\
\text { time-varying signals }\end{array}$} \\
\hline & WT-based & \\
\hline & ST-based & \\
\hline
\end{tabular}

The operating principle of most active and passive methods is based on PLLs or EPLLs. Among the passive methods, the OUV, OUF and ROCOF methods are based on PVS voltage amplitude and frequency information. The PVS PLL or EPLL, used to monitor the PVS operation, can be employed to detect the islanding occurrence operating in coordination with the OUV, OUF and ROCOF relays. Some OUV, OUF and ROCOF protections avoid the PLL and are just based on solid-state relays. The choice depends on the PVS power size, the cost, the desired level of performance. Similarly, many active methods act in order to determine an OUV or OUF in the PVS. When the voltage or the frequency exceeds the threshold value, islanding is detected. It occurs for the active and reactive power injections methods, the AFD, the SFS and the SVS methods. Furthermore, for these methods the main devices are solid-state relays or PLLs/EPLLs coordinated with relays.

Among the passive methods the PJ method requires an additional PLL/EPLL to monitor the PVS current phase which has to be compared to the PVS voltage phase. The VHM requires more PLLS/EPLLs to track the selected harmonics variations and to detect the islanding condition. Among the active methods the SMS method is based on an additional PLL or on a modification of the PVS PLL to create the perturbation in the PVS and to detect the islanding occurrence. In the field of the active methods, just the grid impedance variation method does not require information provided by the PLL/EPLL since it is based on the impedance measurement.

\subsection{Reconnection of a PVS to the Grid after an Islanding Event}

Independently of the adopted islanding detection technique, the reconnection of a PVS after an islanding event needs to be managed by two PLLS or EPLLs circuits. Indeed, an improper reconnection event is not improbable if the PVS breaker $S_{1}$ connects the system to the grid when the PVS voltage is out of phase compared to the grid voltage. In this occasion overcurrents can be verified or, in the worst case, a second disconnection can occur determined by the PVS protections intervention. Hence the reclosing procedure has to be managed in strict coordination with the PVS synchronization system.

Assuming, for example, to detect the islanding condition using the active and reactive power injections method and to employ SOGI PLLs as synchronization systems, in Figure 12 there are shown 
the PVS voltage $e_{P V S}$ and the grid voltage $e$ in case islanding occurs at $t=10 \mathrm{~s}$. At this time, the grid utility breaker Sg is opened and during the islanding operation the amplitude and the frequency of the PVS voltage drift from the rated values.

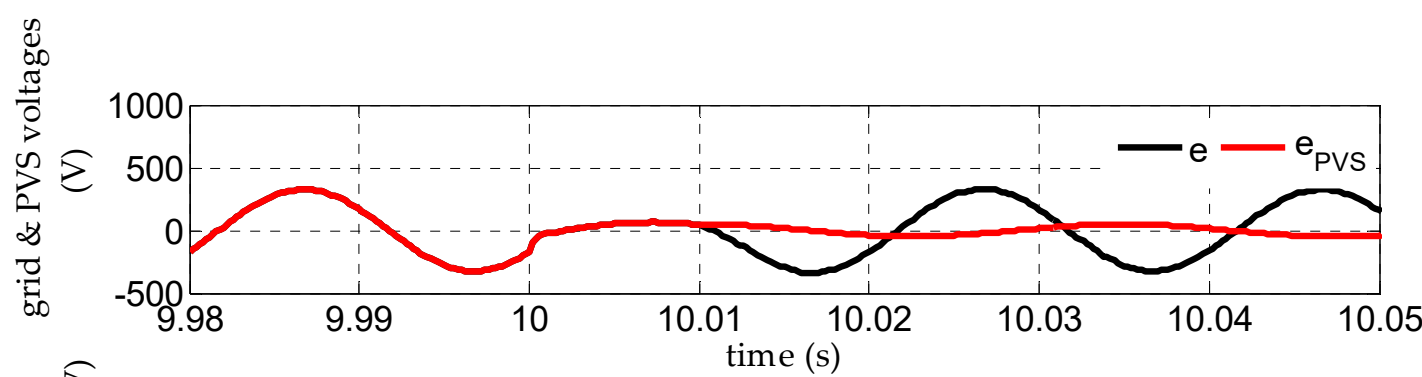

a)

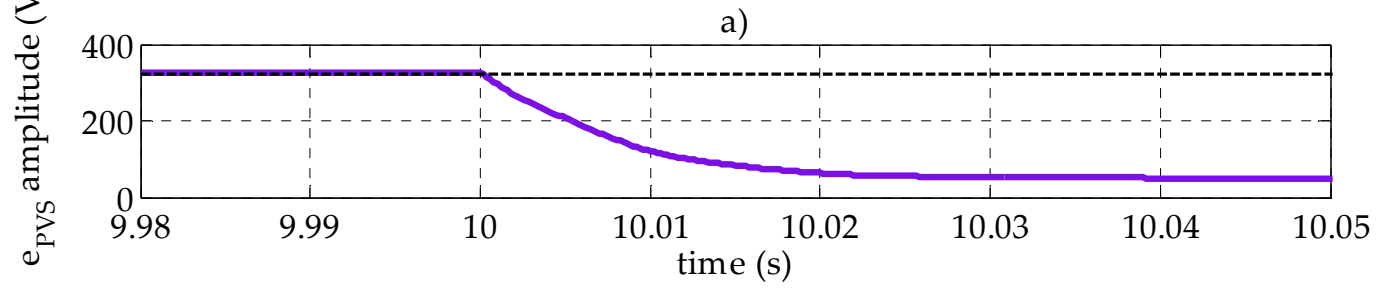

b)

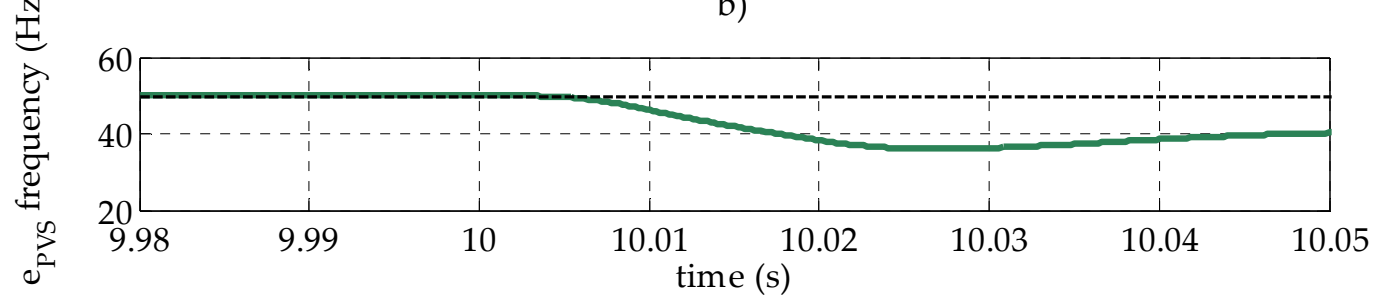

c)

Figure 12. Grid and PVS voltages in case of islanding occurrence. (a) $e$ and $e_{P V S}$ waveforms; (b) $e_{P V S}$ amplitude; (c) $e_{P V S}$ frequency.

The information about the amplitude and the frequency of the PVS voltage, provided by the SOGI $\mathrm{PLL}$, is employed to assess the islanding phenomenon within $2 \mathrm{~s}$ on the basis of the active and reactive power injections method. The grid and the PVS voltage waveforms are not more synchronized and, when the $e_{P V S}$ amplitude and frequency deviations exceed the thresholds values, islanding is detected and also the PVS breaker $S_{1}$ is opened.

Denoting as ID the control signal providing information about the islanding condition, it is possible to define $I D=1$ when islanding is not detected and $I D=0$ when islanding is detected. Similarly, it is possible to use a control signal to assess synchronization of the PVS with the grid. In this analysis it is indicated with synchronization $=1$ the condition when $e_{P V S}$ and $e$ are in-phase, synchronization $=0$ the condition when the two systems are not synchronized.

Assuming that the grid is recovered in few seconds, at $t_{1}=15 \mathrm{~s}$ the grid breaker Sg is closed again (Figure 13). Nevertheless, the reconnection of the PVS cannot be immediate. Since the grid and the PVS are not more synchronized after the islanding occurrence, some reconnection time is required. When the breaker Sg is reclosed, the control signal moves from $I D=0$ to $I D=1$. In the considered case study, the grid recovery is detected in less than $0.03 \mathrm{~s}$, but the PVS is reconnected just at $t_{2}=15.25$.

The PVS reconnection is possible only when $e_{P V S}$ and $e$ are assessed again in-phase. In particular, the synchronization is detected when the phase and the amplitude difference between $e_{P V S}$ and $e$ is null. Only at this time the synchronization control signal moves from synchronization $=0$ to synchronization $=1$.

In the described procedure two PLLs/EPLLs are required: one to monitor the PVS voltage and one to monitor the grid voltage. This example is provided to point out the role of the synchronization 
system and to demonstrate the need of a strict coordination between the islanding detection and the synchronization control units.

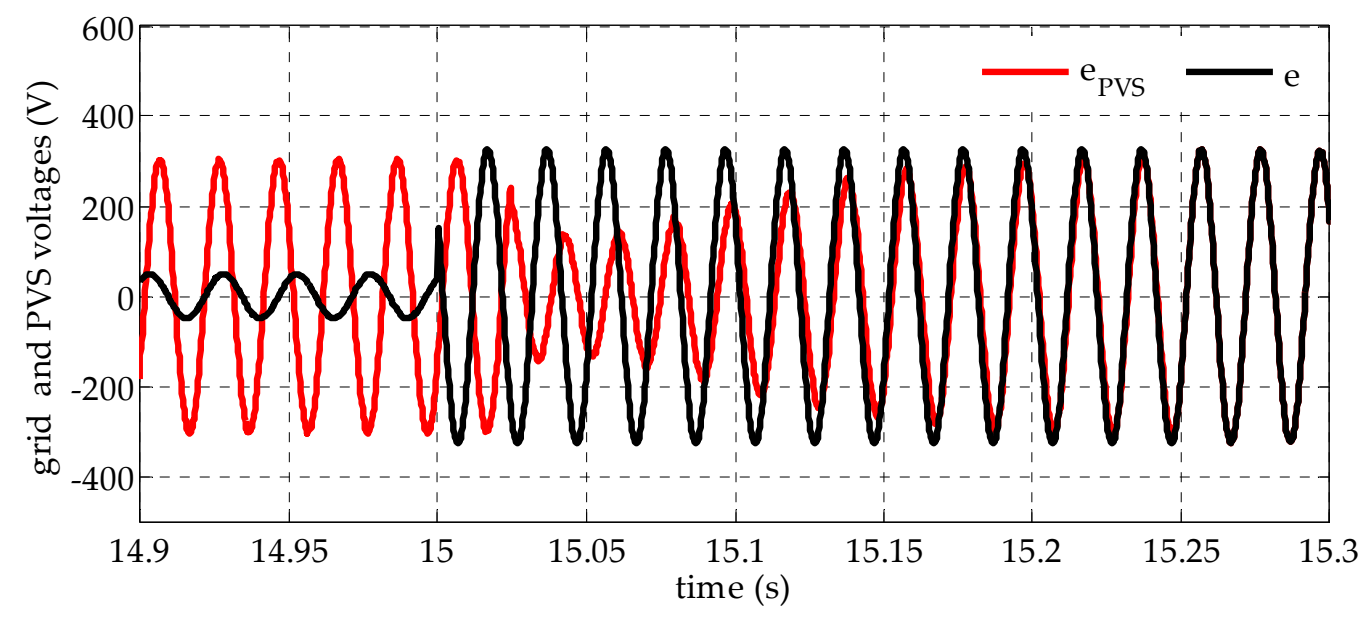

(a)

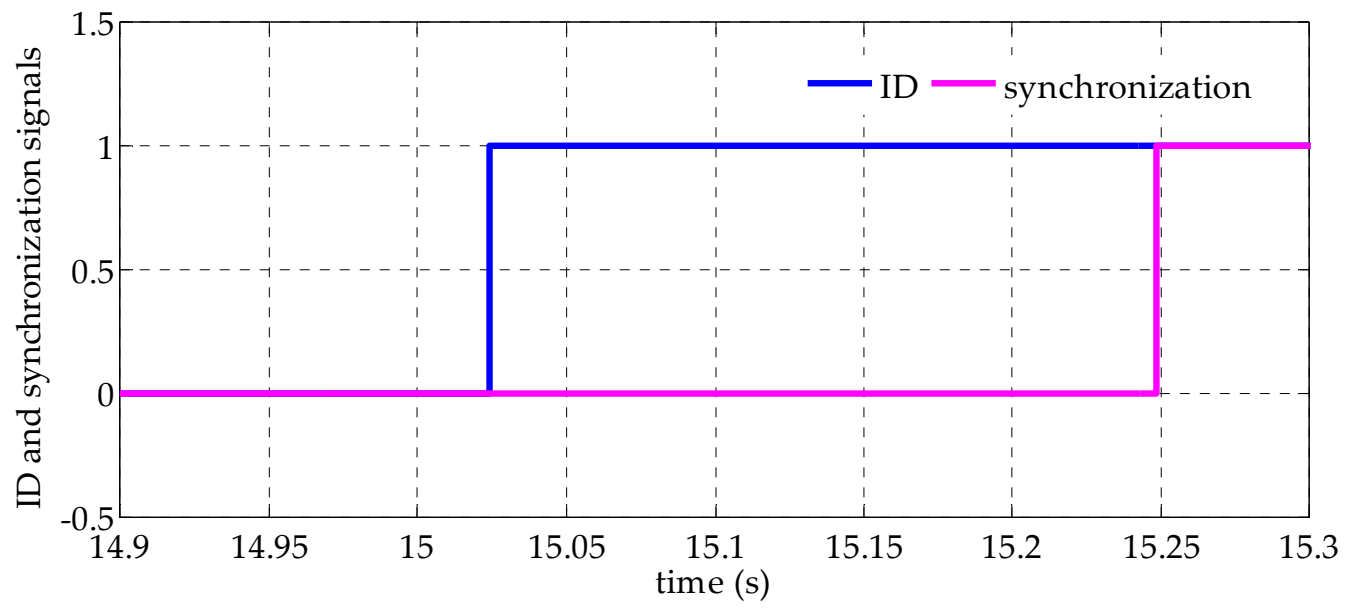

(b)

Figure 13. Grid and PVS voltages during resynchronization process. (a) $e$ and $e_{P V S}$ waveforms; (b) ID and synchronization control signals.

\section{Conclusions}

An extensive analysis of synchronization and islanding detection methods for single-stage PVSs is presented in this study. Synchronization and islanding detection represent some of the most important control issues for PVSs in the light of the new standards requirements. Abnormal conditions can arise on the utility grid which require a prompt response from the grid-connected PVSs, hence the information provided by the synchronization system are fundamental for the grid voltage monitoring.

Synchronization and islanding detection techniques must operate in coordination. The islanding detection techniques are based also on the information provided by the synchronization techniques. Besides some islanding detection methods use additional PLLs for the harmonics monitoring. In other cases, the normal operation of the PLL is modified in order to detect the islanding phenomenon as it happens in case of the slip-mode frequency shift technique. Finally, it has to be considered that, after a disconnection due to the islanding detection, an improper reconnection event is not improbable if the PVS breaker connects the system to the grid when the PVS voltage is out of phase. In this hypothesis a second disconnection can occur due to the PVS protections action. Hence the reclosing procedure has to be managed with two synchronization systems. 
For all these reasons synchronization and islanding detection issues were analyzed together. More than 120 publications were revised and discussed in order to provide a combined review. Both the synchronization and the islanding detection techniques were categorized. The choice of the islanding detection technique depends on numerous criteria. The EPLL and the SOGI PLL represent the preferable synchronization systems to operate in coordination with the islanding detection techniques.

Funding: This research received no external funding.

Conflicts of Interest: The authors declare no conflict of interest.

\section{References}

1. IEA PVPS Annual Report 2019. Available online: https://iea-pvps.org/wp-content/uploads/2020/02/5319-ieapvps-report-2019-08-lr.pdf (accessed on 26 March 2020).

2. Solar PV—Statistics \& Facts, The Statistics Portal. Available online: https://www.statista.com/topics/993/ solar-pv/ (accessed on 15 April 2020).

3. International Renewable Energy Agency IRENA. Renewable Capacity Statistics 2020. Available online: https: //www.irena.org/publications/2020/Mar/Renewable-Capacity-Statistics-2020 (accessed on 26 March 2020).

4. Kausika, B.B.; Moraitis, P.; van Sark, W.G.J.H.M. Visualization of Operational Performance of Grid-Connected PV Systems in Selected European Countries. Energies 2018, 11, 1330. [CrossRef]

5. Ghosh, S.; Rahman, S. Global deployment of solar photovoltaics: Its opportunities and challenges. In Proceedings of the 2016 IEEE PES Innovative Smart Grid Technologies Conference Europe (ISGT-Europe), Ljubljana, Slovenia, 9-12 October 2016; pp. 1-6. [CrossRef]

6. Araujo, S.V.; Zacharias, P.; Mallwitz, R. Highly Efficient Single-Phase Transformerless Inverters for Grid-Connected Photovoltaic Systems. IEEE Trans. Ind. Electron. 2010, 57, 3118-3128. [CrossRef]

7. Olowu, T.O.; Sundararajan, A.; Moghaddami, M.; Sarwat, A.I. Future Challenges and Mitigation Methods for High Photovoltaic Penetration: A Survey. Energies 2018, 11, 1782. [CrossRef]

8. Integrating Renewable Electricity on the Grid-A Report by the APS Panel on Public Affairs, Washington, DC, USA. Available online: https://www.smartgrid.gov/document/integrating_renewable_electricity_grid_ report_aps_panel_public_affairs (accessed on 20 November 2011).

9. Ropp, M.; Newmiller, J.; Whitaker, C.; Norris, B. Review of potential problems and utility concerns arising from high penetration levels of photovoltaics in distribution systems. In Proceedings of the 33rd IEEE Photovoltaic Specialists Conference PVSC '08, San Diego, CA, USA, 11-16 May 2008; pp. 1-6. [CrossRef]

10. Appen, J.V.; Braun, M.; Stetz, T.; Diwold, K.; Geibel, D. Time in the Sun: The Challenge of High PV Penetration in the German Electric Grid. IEEE Power Energy Mag. 2013, 11, 55-64. [CrossRef]

11. Molina-García, A.; Mastromauro, R.A.; García-Sánchez, T.; Pugliese, S.; Liserre, M.; Stasi, S. Reactive Power Flow Control for PV Inverters Voltage Support in LV Distribution Networks. IEEE Trans. Smart Grid 2017, 8, 447-456. [CrossRef]

12. Vasquez, J.C.; Mastromauro, R.A.; Guerrero, J.M.; Liserre, M. Voltage Support Provided by a Droop-Controlled Multifunctional Inverter. IEEE Trans. Ind. Electron. 2009, 56, 4510-4519. [CrossRef]

13. Mastromauro, R.A.; Liserre, M.; Kerekes, T.; Dell'Aquila, A. A Single-Phase Voltage-Controlled Grid-Connected Photovoltaic System with Power Quality Conditioner Functionality. IEEE Trans. Ind. Electron. 2009, 56, 4436-4444. [CrossRef]

14. Koutroulis, E.; Blaabjerg, F. Design Optimization of Transformerless Grid-Connected PV Inverters Including Reliability. IEEE Trans. Power Electron. 2013, 28, 325-335. [CrossRef]

15. Zhang, L.; Sun, K.; Feng, L.; Wu, H.; Xing, Y. A Family of Neutral Point Clamped Full-Bridge Topologies for Transformerless Photovoltaic Grid-Tied Inverters. IEEE Trans. Power Electron. 2013, 28, 730-739. [CrossRef]

16. Freddy, T.K.S.; Rahim, N.A.; Hew, W.; Che, H.S. Comparison and Analysis of Single-Phase Transformerless Grid-Connected PV Inverters. IEEE Trans. Power Electron. 2014, 29, 5358-5369. [CrossRef]

17. Yang, Y.; Blaabjerg, F.; Wang, H. Low-Voltage Ride-Through of Single-Phase Transformerless Photovoltaic Inverters. IEEE Trans. Ind. Appl. 2014, 50, 1942-1952. [CrossRef]

18. Teodorescu, R.; Liserre, M.; Rodriguez, P. Grid Converters for Photovoltaic and Wind Power Systems; IEEE/Wiley: Chichester, UK, 2011. 
19. Mastromauro, R.A.; Liserre, M.; Dell'Aquila, A. Control Issues in Single-Stage Photovoltaic Systems: MPPT, Current and Voltage Control. IEEE Trans. Ind. Inform. 2012, 8, 241-254. [CrossRef]

20. Johnson, B.B.; Dhople, S.V.; Hamadeh, A.O.; Krein, P.T. Synchronization of Parallel Single-Phase Inverters with Virtual Oscillator Control. IEEE Trans. Power Electron. 2014, 29, 6124-6138. [CrossRef]

21. Hadjidemetriou, L.; Kyriakides, E.; Yang, Y.; Blaabjerg, F. A Synchronization Method for Single-Phase Grid-Tied Inverters. IEEE Trans. Power Electron. 2016, 31, 2139-2149. [CrossRef]

22. Shitole, A.B.; Suryawanshi, H.M.; Talapur, G.G.; Sathyan, S.; Ballal, M.S.; Borghate, V.B.; Ramteke, M.R.; Chaudhari, M.A. Grid Interfaced Distributed Generation System with Modified Current Control Loop Using Adaptive Synchronization Technique. IEEE Trans. Ind. Inform. 2017, 13, 2634-2644. [CrossRef]

23. Nagliero, A.; Mastromauro, R.A.; Liserre, M.; Dell'Aquila, A. Monitoring and Synchronization Techniques for Single-Phase PV Systems. In Proceedings of the 2010 International Symposium on Power Electronics, Electrical Drives, Automation and Motion SPEEDAM 2010, Pisa, Italy, 14-16 June 2010; pp. 1404-1409. [CrossRef]

24. Ghartemani, M.K.; Iravani, M.R. A nonlinear adaptative filter for online signal analysis in power systems applications. IEEE Trans. Power Deliv. 2002, 17, 617-622. [CrossRef]

25. IEEE Standard for Interconnection and Interoperability of Distributed Energy Resources with Associated Electric Power Systems Interfaces; IEEE Std 1547-2003; IEEE: Piscataway, NJ, USA, 6 April 2018; pp. 1-138. [CrossRef]

26. Anani, N.; AlAli, O.A.-K.; Al-Qutayri, M.; AL-Araji, S. Synchronization of a renewable energy inverter with the grid. J. Renew. Sustain. Energy 2012, 4. [CrossRef]

27. Lubura, S.; Soja, M.; Lale, S.; Ikić, M. Single-phase phase locked loop with dc offset and noise rejection for photovoltaic inverters. IET Power Electron. 2014, 7, 2288-2299. [CrossRef]

28. Luna, A.; Rocabert, J.; Candela, J.I.; Hermoso, J.R.; Teodorescu, R.; Blaabjerg, F.; Rodríguez, P. Grid Voltage Synchronization for Distributed Generation Systems Under Grid Fault Conditions. IEEE Trans. Ind. Appl. 2015, 51, 3414-3425. [CrossRef]

29. Bower, W.; Ropp, M. Evaluation of Islanding Detection Methods for Utility-Interactive Inverters in Photovoltaic Systems. SANDIA REPORT SAND2002-3591. November 2002. Available online: https://pdfs.semanticscholar. org/2a29/ad6772ffef963d7dfdaece6a9db374e5e3b6.pdf (accessed on 29 March 2020).

30. Zhou, Y.; Li, H.; Liu, L. Integrated Autonomous Voltage Regulation and Islanding Detection for High Penetration PV Applications. IEEE Trans. Power Electron. 2013, 28, 2826-2841. [CrossRef]

31. Yang, F.; Xia, N.; Han, Q. Event-Based Networked Islanding Detection for Distributed Solar PV Generation Systems. IEEE Trans. Ind. Inform. 2017, 13, 322-329. [CrossRef]

32. Baghaee, H.R.; Mlakić, D.; Nikolovski, S.; Dragicčvić, T. Anti-Islanding Protection of PV-Based Microgrids Consisting of PHEVs Using SVMs. IEEE Trans. Smart Grid 2020, 11, 483-500. [CrossRef]

33. Reddy, V.R.; Sreeraj, S.E. A Feedback-Based Passive Islanding Detection Technique for One-Cycle-Controlled Single-Phase Inverter Used in Photovoltaic Systems. IEEE Trans. Ind. Electron. 2020, 67, 6541-6549. [CrossRef]

34. Hung, G.-K.; Chang, C.-C.; Chen, C.-L. Automatic phase-shift method for islanding detection of grid-connected photovoltaic inverters. IEEE Trans. Energy Convers. 2003, 18, 169-173. [CrossRef]

35. Serban, E.; Serban, H. A Control Strategy for a Distributed Power Generation Microgrid Application with Voltage- and Current-Controlled Source Converter. IEEE Trans. Power Electron. 2010, 25, 2981-2992. [CrossRef]

36. IEEE Application Guide for IEEE Std 1547 ${ }^{\mathrm{TM}}$, IEEE Standard for Interconnecting Distributed Resources with Electric Power Systems; IEEE: Piscataway, NJ, USA, April 2009; pp. 1-217. [CrossRef]

37. IEEE Approved Draft Standard Conformance Test Procedures for Equipment Interconnecting Distributed Energy Resources with Electric Power Systems and Associated Interfaces; IEEE P1547.1/D9.9; IEEE: Piscataway, NJ, USA, January 2020; pp. 1-283.

38. IEEE Recommended Practice for Utility Interface of Photovoltaic (PV) Systems; IEEE Std 929-2000; IEEE: New York, NY, USA, 2000. [CrossRef]

39. IEC 61727-2004. Photovoltaic (PV) Systems - Characteristics of the Utility Interface; International Electrotechnical Commission: Geneva, Switzerland, 2004.

40. GB/T 19939-2005. Technical Requirements for Grid Connection of PV System; China National Standardization Administration Committee: Beijing, China, 2005.

41. CIGRE Working Group B5. The Impact of Renewable Energy Sources and Distributed Generation on Substation Protection and Automation; CIGRE: Paris, France, 2010. 
42. Gardner, F.M. Phaselock Techniques, 2nd ed.; Wiley-Interscience: Hoboken, NJ, USA, 1979; p. 304. ISBN -10: 0471042943.

43. Jaalam, N.; Rahim, N.A.; Bakar, A.H.A.; Tan, C.; Haidar, A.M.A. A comprehensive review of synchronization methods for grid-connected converters of renewable energy source. Renew. Sustain. Energy Rev. 2016, 59, 1471-1481. [CrossRef]

44. Guan-Chyun, H.; Hung, J.C. Phase-locked loop techniques. A Survey. IEEE Trans. Ind. Electron. 1996, 43, 609-615. [CrossRef]

45. Golestan, S.; Guerrero, J.M.; Vasquez, J.C. Three-Phase PLLs: A Review of Recent Advances. IEEE Trans. Power Electron. 2017, 32, 1894-1907. [CrossRef]

46. Golestan, S.; Monfared, M.; Freijedo, F. Design-oriented study of advanced synchronous reference frame phase-locked loops. IEEE Trans. Power Electron. 2013, 28, 765-778. [CrossRef]

47. Paiva, S.C.; Sanca, H.S.; Costa, F.B.; Souza, B.A. Reviewing of anti-islanding protection. In Proceedings of the 11th IEEE/IAS International Conference on Industry Applications, Juiz de Fora, Brazil, 7-10 December 2014; pp. 1-8. [CrossRef]

48. Li, C.; Cao, C.; Cao, Y.; Kuang, Y.; Zeng, L.; Fang, B. A review of islanding detection methods for microgrid. Renew. Sustain. Energy Rev. 2014, 35, 211-220. [CrossRef]

49. de Mango, F.; Liserre, M.; Dell'Aquila, A.; Pigazo, A. Overview of anti-islanding algorithms for PV systems. Part I: Passive methods. In Proceedings of the 12th International Power Electronics and Motion Conference, Portoroz, Slovenia, 30 August-1 September 2006; pp. 1878-1883. [CrossRef]

50. de Mango, F.; Liserre, M.; Dell'Aquila, A. Overview of anti-islanding algorithms for PV systems. Part II: Active methods. In Proceedings of the 12th International Power Electronics and Motion Conference, Portoroz, Slovenia, 30 August 30-1 September 2006; pp. 1884-1889. [CrossRef]

51. Abokhalil, A.G.; Awan, A.B.; Al-Qawasmi, A.R. Comparative Study of Passive and Active Islanding Detection Methods for PV Grid-Connected Systems. Sustainability 2018, 10, 1798. [CrossRef]

52. Mahat, P.; Chen, Z.; Bak-Jensen, B. Review of islanding detection methods for distributed generation. In Proceedings of the Third International Conference on Electric Utility Deregulation and Restructuring and Power Technologies, Nanjing, China, 6-8 April 2008; pp. 2743-2748. [CrossRef]

53. Estébanez, E.J.; Moreno, V.M.; Pigazo, A.; Liserre, M.; Dell'Aquila, A. Performance Evaluation of Active Islanding-Detection Algorithms in Distributed-Generation Photovoltaic Systems: Two Inverters Case. IEEE Trans. Ind. Electron. 2011, 58, 1185-1193. [CrossRef]

54. Trujillo, C.L.; Velasco, D.; Figueres, E.; Garcerá, G. Analysis of active islanding detection methods for grid-connected microinverters for renewable energy processing. Appl. Energy 2010, 87, 3591-3605. [CrossRef]

55. Raza, S.; Mokhlis, H.; Arof, H.; Laghari, J.A.; Wang, L. Application of signal processing techniques for islanding detection of distributed generation in distribution network: A review. Energy Convers. Manag. 2015, 96, 613-624. [CrossRef]

56. Manikonda, S.K.G.; Gaonkar, D.N. Comprehensive review of IDMs in DG systems. IET Smart Grid 2019, 2, 11-24. [CrossRef]

57. Khamis, A.; Shareef, H.; Bizkevelci, E.; Khatib, T. A review of islanding detection techniques for renewable distributed generation systems. Renew. Sustain. Energy Rev. 2013, 28, 483-493. [CrossRef]

58. Singh, S.; Kewat, S.; Singh, B.; Panigrahi, B.K.; Kushwaha, M.K. Seamless Control of Solar PV Grid Interfaced System with Islanding Operation. IEEE Power Energy Technol. Syst. J. 2019, 6, 162-171. [CrossRef]

59. Lee, K.J.; Lee, J.P.; Shin, D.; Yoo, D.W.; Kim, H.J. A novel grid synchronization pll method based on adaptive low-pass notch filter for grid-connected pcs. IEEE Trans. Ind. Electron. 2014, 61, 292-301. [CrossRef]

60. Wang, Y.F.; Li, Y.W. A Grid Fundamental and Harmonic Component Detection Method for Single-Phase Systems. IEEE Trans. Power Electron. 2013, 28, 2204-2213. [CrossRef]

61. Karimi-Ghartemani, M. A Unifying Approach to Single-Phase Synchronous Reference Frame PLLs. IEEE Trans. Power Electron. 2013, 28, 4550-4556. [CrossRef]

62. Wall, R.W. Simple methods for detecting zero crossing. In Proceedings of the 29th Annual Conference of the IEEE Industrial Electronics Society IECON'03, Roanoke, VA, USA, 2-6 November 2003; Volume 3, pp. 2477-2481. [CrossRef]

63. Golestan, S.; Monfared, M.; Freijedo, F.D.; Guerrero, J.M. Dynamics Assessment of Advanced Single-Phase PLL Structures. IEEE Trans. Ind. Electron. 2013, 60, 2167-2177. [CrossRef] 
64. Kandeepan, S.; Reisenfeld, S. Frequency tracking and acquisition with a four-quadrant arctan phase detector based digital phase locked loop. In Proceedings of the 2003 Joint Fourth International Conference on Information, Communications and Signal Processing and the Fourth Pacific Rim Conference on Multimedia, Singapore, 15-18 December 2003; Volume 1, pp. 401-405. [CrossRef]

65. Konara, K.M.S.Y.; Kolhe, M.L.; Sankalpa, W.G.C.A. Grid synchronization of DC energy storage using Voltage Source Inverter with ZCD and PLL techniques. In Proceedings of the 2015 IEEE 10th International Conference on Industrial and Information Systems (ICIIS), Peradeniya, Sri Lanka, 18-20 December 2015; pp. 458-462. [CrossRef]

66. Weidenbrug, R.; Dawson, F.P.; Bonert, R. New synchronization method for thyristor power converters to weak AC-systems. IEEE Trans. Ind. Electron. 1993, 40, 505-511. [CrossRef]

67. Mur, F.; Cardenas, V.; Vaquero, J.; Martinez, S. Phase synchronization and measurement digital systems of AC mains for power converters. In Proceedings of the 6th IEEE Power Electronics Congress CIEP 98, Morelia, Mexico, 12-15 October 1998; pp. 188-194. [CrossRef]

68. Choi, J.-W.; Kim, Y.-K.; Kim, H.-G. Digital PLL control for single-phase photovoltaic system. IEE Proc. EE Electr. Power Appl. 2006, 153, 40-46. [CrossRef]

69. Gonzalez-Espin, F.; Figueres, E.; Garcera, G. An Adaptive Synchronous-Reference-Frame Phase-Locked Loop for Power Quality Improvement in a Polluted Utility Grid. IEEE Trans. Ind. Electron 2012, 59, 2718-2731. [CrossRef]

70. Yazdani, D.; Bakhshai, A.; Jain, P. Grid synchronization techniques for converter interfaced distributed generation systems. In Proceedings of the 2009 Energy Conversion Congress and Exposition, ECCE 2009, San Jose, CA, USA, 20-24 September 2009; pp. 2007-2014. [CrossRef]

71. Han, Y.; Luo, M.; Zhao, X.; Guerrero, J.M.; Xu, L. Comparative Performance Evaluation of Orthogonal-Signal-Generators-Based Single-Phase PLL Algorithms-A Survey. IEEE Trans. Power Electron. 2016, 31, 3932-3944. [CrossRef]

72. Yang, Y.; Blaabjerg, F.; Zou, Z. Benchmarking of Grid Fault Modes in Single-Phase Grid-Connected Photovoltaic Systems. IEEE Trans. Ind. Appl. 2013, 49, 2167-2176. [CrossRef]

73. Rodriguez, P.; Teodorescu, R.; Candela, I.; Timbus, A.V.; Laabjerg, F.B. New positive-sequence voltage detector for grid synchronization of power converters under faulty grid conditions. In Proceedings of the 2006 37th IEEE Power Electronics Specialists Conference PESC'06, Jeju, Korea, 18-22 June 2006; pp. 1-7. [CrossRef]

74. Chittora, P.; Singh, A.; Singh, M. Adaptive EPLL for improving power quality in three-phase three-wire grid-connected photovoltaic system. IET Renew. Power Gener. 2019, 13, 1595-1602. [CrossRef]

75. Karimi-Ghartemani, M. Enhanced Phase-Locked Loop Structures for Power and Energy Applications; Wiley-IEEE Press: Piscataway, NJ, USA, 21 March 2014. [CrossRef]

76. Karimi-Ghartemani, M. Linear and Pseudolinear Enhanced Phased-Locked Loop (EPLL) Structures. IEEE Trans. Ind. Electron. 2014, 61, 1464-1474. [CrossRef]

77. Sahoo, A.; Mahmud, K.; Ciobotaru, M.; Ravishankar, J. Adaptive Grid Synchronization Technique for Single-phase Inverters in AC Microgrid. In Proceedings of the 2019 IEEE Energy Conversion Congress and Exposition (ECCE), Baltimore, MD, USA, 29 September-3 October 2019; pp. 4441-4446. [CrossRef]

78. Task V Report IEA-PVPS T5-09:2002, Evaluation of Islanding Detection Methods for Photovoltaic Utility-Interactive Power Systems. Available online: https://iea-pvps.org/wp-content/uploads/2020/01/ rep5_09.pdf (accessed on 15 December 2002).

79. Ye, Z.; Kolwalkar, A.; Zhang, Y.; Du, P.; Walling, R. Evaluation of anti-islanding schemes based on nondetection zone concept. IEEE Trans. Power Electron. 2004, 19, 1171-1176. [CrossRef]

80. Ropp, M.E.; Begovic, M.; Rohatgi, A.; Kern, G.A.; Bonn, R.H.; Gonzalez, S. Determining the relative effectiveness of islanding detection methods using phase criteria and nondetection zones. IEEE Trans. Energy Convers. 2000, 15, 290-296. [CrossRef]

81. IEEE Standard for Interconnecting Distributed Resources with Electric Power Systems; IEEE Std 1547-2003; IEEE: Piscataway, NJ, USA, 1-28 July 2003. [CrossRef]

82. Shrestha, A.; Kattel, R.; Dachhepatic, M.; Mali, B.; Thapa, R.; Singh, A.; Bista, D.; Adhikary, B.; Papadakis, A.; Maskey, R.K. Comparative Study of Different Approaches for Islanding Detection of Distributed Generation Systems. Appl. Syst. Innov. 2019, 2. [CrossRef] 
83. Samuelsson, O.; Strath, N. Islanding detection and connection requirements. In Proceedings of the 2007 IEEE Power Engineering Society General Meeting, Tampa, FL, USA, 24-28 June 2007; pp. 1-6. [CrossRef]

84. Ropp, M.; Larson, D.; Meendering, S.; MacMahon, D.; Ginn, J.; Stevens, J.; Bower, W.; Gonzalez, S.; Fennell, K.; Brusseau, L. Discussion of power line carrier communications-based anti-islanding scheme using a commercial automatic meter reading system. In Proceedings of the 4th IEEE World Conference on Photovoltaic Energy Conversion, Waikoloa, HI, USA, 7-12 May 2006; pp. 2351-2354. [CrossRef]

85. Benato, R.; Caldon, R. Distribution line carrier: Analysis procedure and applications to DG. IEEE Trans. Power Deliv. 2007, 22, 575-583. [CrossRef]

86. Xu, W.; Zhang, G.; Li, C.; Wang, W.; Wang, G.; Kliber, J. A power line signaling based technique for anti-islanding protection of distributed generators-Part i: Scheme and analysis. IEEE Trans. Power Deliv. 2007, 22, 1758-1766. [CrossRef]

87. Wang, G.; Kliber, J.; Zhang, G.; Xu, W.; Howell, B.; Palladino, T. A power line signaling based technique for anti-islanding protection of distributed generators_Part ii: Field test results. IEEE Trans. Power Deliv. 2007, 22, 1767-1772. [CrossRef]

88. Aphrodis, N.; Ntagwirumugara, E.; Vianney, B.J.M.; Mulolani, F. Design, Control and Validation of a PV System Based on Supervisory Control and Data Acquisition (SCADA) Viewer in Smartgrids. In Proceedings of the 5th International Conference on Control, Automation and Robotics (ICCAR), Beijing, China, 19-22 April 2019; pp. 23-28. [CrossRef]

89. Etxegarai, A.; Egua, P.; Zamora, I. Analysis of remote islanding detection methods for distributed resources. In Proceedings of the International Conference on Renewable Energies and Power Quality (ICREPQ'11), Las Palmas, Spain, 13-15 April 2011; pp. 1142-1147. Available online: http://www.icrepq.com/icrepq|T1\ textquoteright11/580-etxegarai.pdf (accessed on 29 March 2020).

90. Vieira, W.X.J.C.; Freitas, W.; Morelato, A. Performance of frequency relays for distributed generation protection. IEEE Trans. Power Deliv. 2006, 21, 1120-1127. [CrossRef]

91. Freitas, W.; Xu, W.; Affonso, C.M.; Huang, Z. Comparative analysis between ROCOF and vector surge relays for distributed generation applications. IEEE Trans. Power Deliv. 2005, 20, 1315-1324. [CrossRef]

92. Ten, C.F.; Crossley, P.A. Evaluation of Rocof Relay Performances on Networks with Distributed Generation. In Proceedings of the 2008 IET 9th International Conference on Developments in Power System Protection (DPSP 2008), Glasgow, Scotland, 17-20 March 2008; pp. 523-528. [CrossRef]

93. de la Fuente, D.V.; Rodriguez, C.L.T.; Narvaez, E.A. Review of Anti-Islanding Methods: Analysis by Figures of Merit Tools for Controllers Reconfiguration in Microgrids. IEEE Lat. Am. Trans. 2015, 13, 679-686. [CrossRef]

94. Timbus, A.V.; Teodorescu, R.; Blaabjerg, F.; Borup, U. Online grid measurement and ENS detection for PV inverter running on highly inductive grid. IEEE Power Electron. Lett. 2004, 2, 77-82. [CrossRef]

95. Asiminoaei, L.; Teodorescu, R.; Blaabjerg, F.; Borup, U. A digital controlled PV-inverter with grid impedance estimation for ENS detection. IEEE Trans. Power Electron. 2005, 20, 1480-1490. [CrossRef]

96. Jeraputra, P.N. Enjeti, Development of a robust anti-islanding algorithm for utility interconnection of distributed fuel cell powered generation. IEEE Trans. Power Electron. 2004, 19, 1163-1170. [CrossRef]

97. Du, P.; Ye, Z.; Aponte, E.E.; Nelson, J.K.; Fan, L. Positive-Feedback-Based Active Anti-Islanding Schemes for Inverter-Based Distributed Generators: Basic Principle, Design Guideline and Performance Analysis. IEEE Trans. Power Electron. 2010, 25, 2941-2948. [CrossRef]

98. Zeineldin, H.H.; Conti, S. Sandia frequency shift parameter selection for multi-inverter systems to eliminate non-detection zone. IET Renew. Power Gener. 2011, 5, 175-183. [CrossRef]

99. Reis, M.V.G.; Barros, T.A.S.; Moreira, A.B.; Nascimento, S.F.P.; Ruppert, F.E.; Villalva, M.G. Analysis of the Sandia Frequency Shift (SFS) islanding detection method with a single-phase photovoltaic distributed generation system. In Proceedings of the 2015 IEEE PES Innovative Smart Grid Technologies Latin America ISGT LATAM 2015, Montevideo, Uruguay, 5-7 October 2015; pp. 125-129. [CrossRef]

100. El-Moubarak, M.; Hassan, M.; Faza, A. Performance of three islanding detection methods for grid-tied multi-inverters. In Proceedings of the 2015 IEEE 15th International Conference on Environment and Electrical Engineering (EEEIC), Rome, Italy, 10-13 June 2015; pp. 1999-2004. [CrossRef]

101. Mohammadpour, B.; Zareie, M.; Eren, S.; Pahlevani, M. Stability analysis of the slip mode frequency shift islanding detection in single phase PV inverters. In Proceedings of the 2017 IEEE 26th International Symposium on Industrial Electronics (ISIE), Edinburgh, UK, 19-21 June 2017; pp. 873-878. [CrossRef] 
102. Mohammadpour, B.; Pahlevani, M.; Kaviri, S.M.; Jain, P. Advanced slip mode frequency shift islanding detection method for single phase grid connected PV inverters. In Proceedings of the 2016 IEEE Applied Power Electronics Conference and Exposition (APEC), Long Beach, CA, USA, 20-24 March 2016; pp. 378-385. [CrossRef]

103. Gu, Y.H.; Bollen, M.H.J. Time-Frequency and Time-Scale Domain Analysis of Voltage Disturbances. IEEE Trans. Power Deliv. 2000, 15, 1279-1284. [CrossRef]

104. Kim, I.-S. Islanding Detection Technique using Grid-Harmonic Parameters in the Photovoltaic System. Energy Procedia 2012, 14, 137-141. [CrossRef]

105. Kim, J.; Kim, J.; Ji, Y.; Jung, Y.; Won, C. An Islanding Detection Method for a Grid-Connected System Based on the Goertzel Algorithm. IEEE Trans. Power Electron. 2011, 26, 1049-1055. [CrossRef]

106. Hanif, M.; Basu, M.; Gaughan, K. Development of EN50438 compliant wavelet-based islanding detection technique for three-phase static distributed generation systems. IET Renew. Power Gener. 2012, 6, $289-301$. [CrossRef]

107. Zhu, Y.; Yang, Q.; Wu, J.; Zheng, D.; Tian, Y. A novel islanding detection method of distributed generator based on wavelet transform. In Proceedings of the 2008 International Conference on Electrical Machines and Systems, Wuhan, China, 17-20 October 2008; pp. 2686-2688.

108. Ning, J.; Wang, C. Feature extraction for islanding detection using Wavelet Transform-based Multi-Resolution Analysis. In Proceedings of the 2012 IEEE Power and Energy Society General Meeting, San Diego, CA, USA, 22-26 July 2012; pp. 1-6. [CrossRef]

109. Hsieh, C.-T.; Lin, J.-M.; Huang, S.-J. Enhancement of islanding-detection of distributed generation systems via wavelet transform-based approaches. Int. J. Electr. Power Energy Syst. 2008, 30, 575-580. [CrossRef]

110. Do, H.T.; Zhang, X.; Nguyen, N.V.; Li, S.S.; Chu, T.T. Passive-Islanding Detection Method Using the Wavelet Packet Transform in Grid-Connected Photovoltaic Systems. IEEE Trans. Power Electron. 2016, 31, 6955-6967. [CrossRef]

111. Pigazo, A.; Liserre, M.; Mastromauro, R.A.; Moreno, V.M.; Dell'Aquila, A. Wavelet-Based Islanding Detection in Grid-Connected PV Systems. IEEE Trans. Ind. Electron. 2009, 56, 4445-4455. [CrossRef]

112. Ray, P.; Mohanty, S.; Kishor, S.; Dubey, H. Coherency determination in grid connected distributed generation based hybrid system under islanding scenarios. In Proceedings of the IEEE International Conference on Power and Energy (PECon2010), Kuala Lumpur, Malaysia, 29 November-1 December 2010; pp. 85-88. [CrossRef]

113. Ray, P.; Kishor, N.; Mohanty, S. S-Transform based islanding detection in grid connected distributed generation based power system. In Proceedings of the 2010 IEEE International Energy Conference (ENERGYCON2010), Manama, Bahrain, 18-22 December 2010; pp. 612-617. [CrossRef]

114. Ray, P.; Mohanty, S.; Kishor, N. Disturbance detection in grid-connected distributed generation system using wavelet and S-Transform. Electr. Power Syst. Res. 2011, 81, 805-819. [CrossRef]

115. Quoc-Tuan, T. New methods of islanding detection for photovoltaic inverters. In Proceedings of the 2016 IEEE PES Innovative Smart Grid Technologies Conference Europe (ISGT-Europe), Ljubljana, Slovenia, 9-12 October 2016; pp. 1-5. [CrossRef]

116. Liu, S.; Zhuang, S.; Xu, Q.; Xiao, J. Improved voltage shift islanding detection method for multi-inverter grid-connected photovoltaic systems. IET Gener. Transm. Distrib. 2016, 10, 3163-3169. [CrossRef]

117. Dhar, S.; Dash, P.K. Harmonic Profile Injection-Based Hybrid Active Islanding Detection Technique for PV-VSC-Based Microgrid System. IEEE Trans. Sustain. Energy 2016, 7, 1473-1481. [CrossRef]

118. Yu, B.; Matsui, M.; So, J.; Yu, G. A high power quality anti-islanding method using effective power variation. Sol. Energy 2008, 82, 368-378. [CrossRef]

119. Yu, B.; Matsui, M.; Jung, Y.; Yu, G. A combined active anti-islanding method for photovoltaic systems. Renew. Energy 2008, 33, 979-985. [CrossRef]

120. Muñoz-Cruzado-Alba, J.; Villegas-Núñez, J.; Vite-Frías, J.A.; Carrasco-Solís, J.M.; Galván-Díez, E. New Low-Distortion Q-f Droop Plus Correlation Anti-Islanding Detection Method for Power Converters in Distributed Generation Systems. IEEE Trans. Ind. Electron. 2015, 62, 5072-5081. [CrossRef]

121. Papadimitriou, C.N.; Kleftakis, V.A.; Hatziargyriou, N.D. A novel islanding detection method for microgrids based on variable impedance insertion. Electr. Power Syst. Res. 2015, 121, 58-66. [CrossRef] 
122. Vyas, S.; Kumar, R. Computational geometry-based methodology for identification of potential islanding initiators in high solar PV penetration distribution feeders. IET Renew. Power Gener. 2018, 12, 456-462. [CrossRef]

123. Voglitsis, D.; Papanikolaou, N.P.; Kyritsis, A.C. Active Cross-Correlation Anti-Islanding Scheme for PV Module-Integrated Converters in the Prospect of High Penetration Levels and Weak Grid Conditions. IEEE Trans. Power Electron. 2019, 34, 2258-2274. [CrossRef]

124. Baghaee, H.R.; Mlakić, D.; Nikolovski, S.; Dragičević, T. Support Vector Machine-based Islanding and Grid Fault Detection in Active Distribution Networks. IEEE J. Emerg. Sel. Top. Power Electron. 2019. [CrossRef]

125. Eshraghi, A.; Ghorbani, R. Islanding detection and over voltage mitigation using controllable loads. Sustain. Energy Grids Netw. 2016, 6, 125-135. [CrossRef]

(C) 2020 by the author. Licensee MDPI, Basel, Switzerland. This article is an open access article distributed under the terms and conditions of the Creative Commons Attribution (CC BY) license (http://creativecommons.org/licenses/by/4.0/). 